\title{
Otimização multiobjetivo orientada ao desempenho térmico para o projeto de edificações de baixo consumo de energia na Região Sul do Brasil
}

\author{
Multi-objective optimisation targeted at the thermal \\ performance of low-energy buildings design in southern \\ Brazil
}

\section{Vinícius Cesar Cadena Linczuk Leopoldo Eurico Gonçalves Bastos}

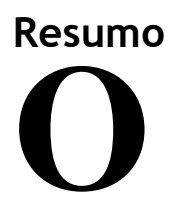

objetivo deste artigo é apresentar o potencial de uma otimização multiobjetivo orientada para soluções de projeto arquitetônico que contemplem melhores condições de conforto térmico e redução do consumo de energia. Para tanto, o estudo é aplicado a um modelo constituído de única zona térmica, para o qual foram considerados distintos valores para os parâmetros construtivos. São considerados para o envelope: a orientação solar, as propriedades dos materiais opacos e transparentes da envoltória, as dimensões da janela e da proteção solar. Utilizou-se nas simulações o software EnergyPlus associado à ferramenta de parametrização e otimização JEPlus+EA. O processo de otimização visa minimizar os indicadores de graus-hora para aquecimento (GHa) e de resfriamento (GHr). Essa minimização revela-se de interesse para as cidades situadas na Região Sul do Brasil de clima temperado úmido, nas quais há necessidade de adoção de estratégias de projeto conflitantes em função das condições de inverno e verão. Os resultados para as configurações dos envelopes e orientação de implantação do modelo são apresentados por meio da Fronteira de Pareto. Assim, torna-se possível identificar a relação entre os diversos parâmetros de projeto assumidos, com a minimização dos requerimentos estabelecidos de consumo de energia para o modelo arquitetônico analisado.

Palavras-chave: Otimização multiobjectivo. Algoritmos genéticos. Edificações de baixo consumo de energia.

\section{Abstract}

The aim of this paper is to present the potential of a multi-objective optimisation of architectural design solutions that offer better thermal comfort conditions and lower energy consumption. The study was applied in a rectangular box model as a single thermal zone, and different values were considered for the constructive parameters of the building. In addition, the following elements of the envelope were also analysed: solar orientation, the properties of opaque and transparent

${ }^{1}$ Vinícius Cesar Cadena Linczuk ${ }^{1}$ Universidade Federal da Fronteira Sul Erechim - RS - Brasil

2, ${ }^{3}$ Leopoldo Eurico Gonçalves Bastos

${ }^{2}$ Universidade Federal do Rio de Rio de Janeiro - RJ - Brasil ${ }^{3}$ Universidade Vila Velha Vila Velha - ES - Brasil

Recebido em 09/08/19 Aceito em 30/10/19 materials, window dimensions and sunshade. The EnergyPlus software associated with the JEPlus + EA parameterisation and optimisation tool were used for the simulations. The optimisation process considered the minimisation for both the Heating Degree Hours (GHa) and Cooling Degree Hours (GHr). This

minimisation is interesting for cities with a humid temperate climate in southern Brazil, where it is necessary to adopt conflicting building design strategies due to the different winter and summer conditions. The results for the envelope configurations for one given model site orientation are presented through the Pareto Frontier. Hence, it is possible to identify the relationship between the various designed parameters assumed, with the minimisation of the established energy consumption requirements for the architectural model analysed.

Keywords: Multi-objective optimisation. Genetic algorithms. Low-energy buildings. 


\section{Introdução}

No Brasil, as pesquisas relacionadas às edificações com baixo ou zero consumo de energia (caso de autossuficiência energética) ainda se encontram em estágio inicial. Em 2003 foi instituído o Programa Nacional de Eficiência Energética em Edificações e, a partir de 2009, publicados os Regulamentos Técnicos de Qualidade Nacional de Conservação de Energia (FOSSATI et al., 2016). Para as edificações residenciais o regulamento mais recente é de 2012 e apresenta caráter voluntário (INMETRO, 2012). As normatizações brasileiras têm estimulado a melhoria dos padrões construtivos, como também das condições internas do ambiente construído, além da redução do consumo energético para condicionamento ativo; contudo, não estabelecem restrições orientadas ao alcance de níveis mais rigorosos de eficiência energética. O que se observa, no entanto, é que o crescimento populacional associado ao aumento do bem-estar social tem levado a um aumento do consumo de energia elétrica para propiciar condições de conforto térmico nos ambientes interiores. No Brasil o setor residencial representa 28,8\% do consumo total de energia elétrica, enquanto na Região Sul o setor residencial alcança 25\%, com um consumo médio de 177 kWh/mês (EPE, 2018).

Verifica-se no Brasil que muitos estudos relacionados com as edificações de baixíssimo consumo energético têm se concentrado em viabilizar o padrão europeu de edificações altamente isoladas, embora estas sejam referentes a outra realidade climática e cultural. Schnieders et al. (2012) trataram da aplicabilidade do padrão alemão Passivhaus para vários climas, incluindo os do Brasil. Wassouf (2014) também enfocou o mesmo padrão em localidades de clima quente, como o Rio de Janeiro. Tubelo et al. (2014) compararam o Regulamento Técnico de Qualidade para Edificações Residenciais (RTQ-R) (INMETRO, 2012) com esse mesmo padrão. Pacheco (2014) avaliou a aplicabilidade de edificações de energia zero, de padrão superisolado, no Brasil em relação à adoção de sistemas de ventilação natural ou climatização artificial. Dalbem et al. (2016) estudaram uma edificação unifamiliar com especificações Passivhaus para climas quentes, aplicada ao clima subtropical úmido de Pelotas, RS. Dalbem (2018) considerou melhorias ao desempenho de uma habitação de interesse social seguindo normativas brasileiras, a NBR 15.575:2013 e para o Nível A do RTQ-R. Além disso, para o contexto climático do sul do Brasil considerou condições de adequação do padrão alemão sob os enfoques energético e econômico. As melhorias proporcionaram redução do consumo de energia, mas acarretaram custos $40 \%$ maiores, quando comparado aos de uma edificação tradicional. Tubelo et al. (2018) realizaram simulações termoenergéticas para um modelo de habitação de interesse social, implantado em três cidades nas Regiões Sul e Sudeste do Brasil, onde consideraram a aplicação de isolamento térmico e a redução da infiltração de ar, além dos custos associados.

O modelo de edificações altamente isoladas, no entanto, tem demonstrado que apresenta restrições quanto à sua adaptabilidade a diferentes climas sob os pontos de vista tecnológico, financeiro e cultural. Pacheco e Lamberts (2013) alertam sobre as possíveis restrições culturais a esse modelo, devido às esquadrias seladas, baixa infiltração de ar e aberturas com pequenas dimensões. Considera-se pelo exposto que é complexa a problemática da habitação voltada para um baixo consumo energético, pois envolve muitos critérios de projeto e ambientais. Dessa forma, revelam-se de importância estudos mais aprofundados para essa temática de edificações com baixíssimo consumo energético, principalmente para o contexto do sul brasileiro, onde se verifica a necessidade de adoção de estratégias de projeto conflitantes em função das condições ambientais de inverno e verão.

Na Europa, nos últimos anos, com o intuito de satisfazer requisitos rigorosos para obtenção de edificações de alto desempenho energético, e atender aos apontamentos de diretivas (EPBD-2010/31/UE), diversos pesquisadores têm realizado estudos avançados de otimização baseada em simulação computacional (EVINS, 2013; MACHAIRAS et al., 2014, NGUYEN et al. 2014). A abordagem multiobjetivo através da otimização tem sido bem utilizada para resolução de problemas frequentemente conflitantes, como, por exemplo, a maximização das condições de conforto higrotérmico no ambiente construído sob um mínimo dispêndio de energia, ao lado de um custo mínimo de construção. A viabilidade da otimização multiobjetivo tem sido conseguida através da melhoria dos recursos computacionais, da possibilidade do processamento em paralelo, ou em nuvem, assim como da integração de algoritmos aos programas de simulação termoenergética (ATTIA et al., 2013).

O objetivo deste artigo é apresentar o potencial de uma otimização multiobjetivo orientada para soluções de projeto arquitetônico que contemplem melhores condições de conforto térmico e redução do consumo de energia de edificações residenciais. $\mathrm{O}$ estudo trata em particular da especificidade climática da Região Sul do Brasil, que apresenta clima temperado no qual as condições de inverno e verão refletem na adoção de estratégias de projeto conflitantes. O estudo deteve-se na minimização dos indicadores de graus-hora para 
aquecimento (GHa) e de resfriamento ( $\mathrm{GHr}$ ), e os resultados apresentados por meio da Fronteira de Pareto revelam um conjunto de soluções.

\section{Otimização multiobjetivo}

\section{Uma nova abordagem para a simulação termoenergética do edifício}

A fase de concepção do projeto arquitetônico se caracteriza por uma série de tomadas de decisão do projetista com relação a uma grande quantidade de parâmetros e níveis de variações. Portanto, são escolhas que consideram questões normativas, restrições impostas pelos códigos de obras, área construída, aspectos visuais, desníveis no terreno, questões estéticas, aspectos técnicos, requisitos de estrutura e outros tantos. Somente relativo ao conforto ambiental há uma multiplicidade de fatores da edificação que o influenciam diretamente como: orientação solar, propriedades físicas dos materiais opacos e transparentes da envoltória, dimensões das janelas, proteção solar e taxa de renovação do ar.

Assim, em consequência dessas questões de projeto, tem se tornado comum a utilização de ferramentas de simulação computacional para a avaliação das condições de conforto ambiental e eficiência energética nos edifícios. Geralmente os projetistas executam simulações paramétricas em uma análise que considera só um critério, em uma abordagem denominada OAT (one-at-a-time approach), ou seja, um parâmetro por vez (ØSTERGÅRD et al., 2016). No entanto, conforme indicam Tuhus-Dubrow e Krarti (2010), alterar um parâmetro enquanto são fixados os demais constantes pode ocasionar a perda de importantes efeitos interativos, tornar o processo repetitivo, frequentemente demorado e, portanto, não completamente confiável (DELGARM et al, 2016).

Attia et al. (2013) mencionam que geralmente as simulações termoenergéticas têm negligenciado o conforto visual e a qualidade do ar interno. Delgarm et al. (2016) apontam conflitos quando é grande o número de variáveis, como também entre os objetivos estabelecidos. Nesse sentido, decisões sobre o desempenho térmico podem acarretar impactos em outras esferas, como, por exemplo, no conforto lumínico, na qualidade do ar, ou sobre os custos. Tuhus-Dubrow e Krarti (2010) indicam que a consideração de fatores econômicos ainda torna mais complexo o problema da eficiência energética na edificação.

A nova perspectiva de uma abordagem multiobjetivo por meio de processos de otimização possibilita uma percepção holística (EVINS, 2013) frente à diversidade combinatória apresentada pelas variáveis de projeto. Para Østergård et al. (2016) o projeto holístico contempla o cálculo de muitos objetivos de desempenho interdependentes e oferece um melhor suporte à tomada de decisão pelos projetistas. $\mathrm{O}$ processo tem se demonstrado vantajoso pela automatização da busca por melhores soluções dentro de objetivos e restrições definidos inicialmente pelo projetista. Assim, o método apresentado para a otimização multiobjetivo do desempenho dos edifícios acarreta uma grande redução do tempo computacional comparado a uma busca completa de combinações.

\section{Como funciona a otimização multiobjetivo?}

Shi et al. (2016) consideram o projeto eficiente e a otimização de edifícios sob a perspectiva dos arquitetos, e ressaltam a grande responsabilidade destes e dos engenheiros mecânicos, para alcançar um projeto de edifício eficiente. As decisões que esses profissionais tomam impactam diretamente nas cargas de aquecimento, resfriamento do edifício e, consequentemente, refletem na economia de energia. Os autores esclarecem que a otimização é uma técnica promissora para um projeto com eficiência energética, e melhor desempenho global, embora haja obstáculos e a necessidade de mais pesquisas. Segundo esses autores, os algoritmos de otimização têm sido tipicamente objeto da ciência da computação e da matemática, e a sua introdução no campo da arquitetura é relativamente nova. Kheiri (2018) apresenta o estado da arte sobre a otimização do projeto relacionado com a forma e o envelope construtivo para fins de eficiência energética. Sua pesquisa contempla uma atualização de estudos anteriores na área de otimização de energia, pela maior aplicação na construção civil em 2000, 2007 e principalmente após 2014.

O processo de busca da solução de um problema é geralmente automatizado por meio do acoplamento entre um programa de simulação de edifícios e um motor de otimização (ATTIA, 2012), conforme mostrado na Figura 1. A partir de funções-objetivo previamente definidas e configurados os procedimentos particulares de cada algoritmo, o programa de otimização gerencia o processo, insere os dados de entrada ao programa de simulação e apresenta como saída os resultados obtidos. O procedimento de melhoria segundo os objetivos estipulados é contínuo até que sejam satisfeitos os critérios de interrupção e, por fim, apresentados os resultados. 
Figura 1 - Esquema de acoplamento aplicado à otimização baseada em simulação

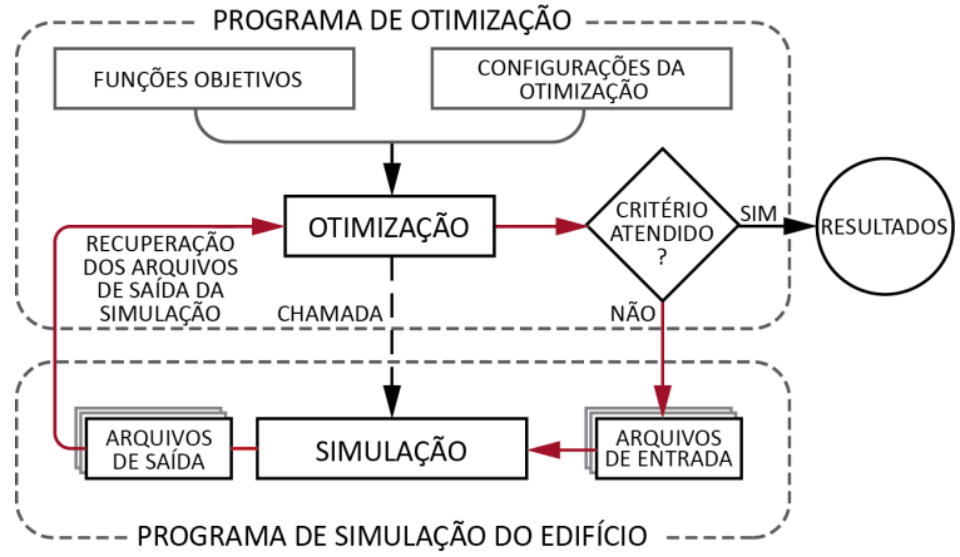

Fonte: adaptado de Nguyen et al. (2014, p. 1045).

No estudo da otimização multiobjetivo via simulação computacional, podem ser aplicados métodos clássicos que compreendem, geralmente, na soma ponderada dos diversos objetivos ou em uma função de critério global, transformando o problema em mono-objetivo. Dentre eles, os mais comumente utilizados são: Método da Soma Ponderada (WSM-Weighted Sum Method); Método E-Restrito (E-Constraint Method); e Método da Distância Ponderada (Weight Metric Method) (DEB, 2001).

Outra opção é a aplicação de métodos que utilizam algoritmos evolutivos, que consistem na otimização por rápidos processos intuitivos de escolha. DEB (2001) lista alguns algoritmos evolutivos para a resolução de problemas multiobjetivos:

(a) VEGA (Vector Evaluated Genetic Algorithm);

(b) WBGA (Weight-based Genetic Algorithm);

(c) MOGA (Multi-Objective Genetic Algorithm);

(d) NPGA (Niched Pareto Genetic Algorithm);

(e) NSGA (Non-Dominated Sorting Genetic Algorithm);

(f) SPEA (Strength Pareto Evolutionary Algorithm);

(g) SPEA-II (Strength Pareto Evolutionary Algorithm II);

(h) MEA (Multi-objective Evolutionary Algorithm); e

(i) NSGA-II (Elitist Non-Dominated Sorting Genetic Algorithm) (DEB et al., 2002).

O algoritmo genético foi introduzido por Holland (1975) e se baseia em um processo natural de seleção e adaptação que imita a evolução biológica, incluindo aspectos de herança, cruzamento ou combinação e mutação. Uma solução é representada por um código, uma sequência de bits, que corresponde ao cromossomo, cada posição de bit é chamada de gene e os valores de cada gene representam os alelos. A Figura 2 ilustra o processo de cruzamento que consiste na divisão dos cromossomos em duas partes que, na sequência, são recombinadas.

Em geral, o processo de otimização com um algoritmo genético consiste inicialmente em criar uma população com boa distribuição, ou seja, diversificada em suas características, e aplicar uma avaliação por meio de uma função-objetivo de minimização ou maximização de aptidão, denominada de fitness. Indivíduos mais aptos terão maior chance de perpetuar seus genes em um processo de cruzamento, indicado como crossover. Com a geração de novos indivíduos, em um processo contíguo, a mutação ocorre para trazer maior variabilidade à população. Sucessivamente as novas gerações são avaliadas até ser satisfeito o critério de parada, conforme esquema ilustrado na Figura 3.

O resultado do processo de otimização multiobjetivo é principalmente verificado por meio da avaliação de um diagrama de Pareto (PARETO, 1896), compreendido por um espaço formado pelas funções-objetivo do problema, conforme Figura 4. 
Figura 2 - Processo de cruzamento do algoritmo genético

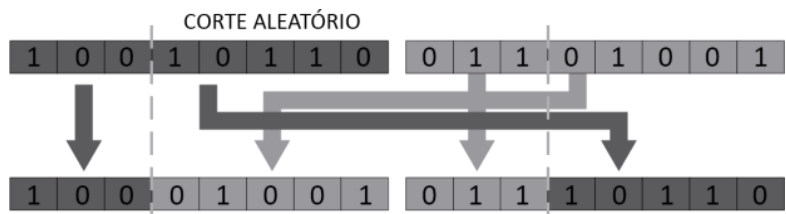

Fonte: adaptado de Branco e Santos (2012).

Figura 3 - Procedimento de execução do algoritmo genético

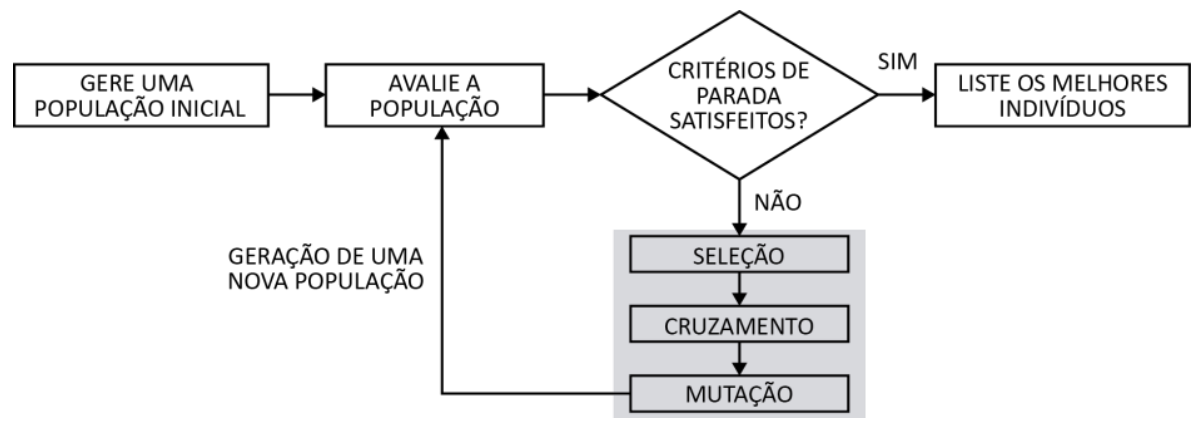

Fonte: adaptado de Branco e Santos (2012).

Figura 4 - Diagrama de Pareto

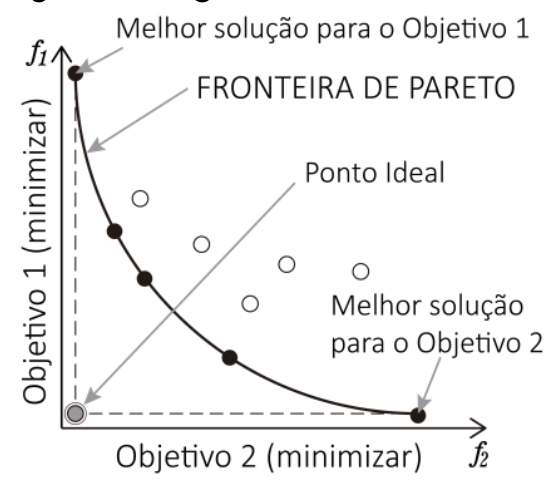

(a)

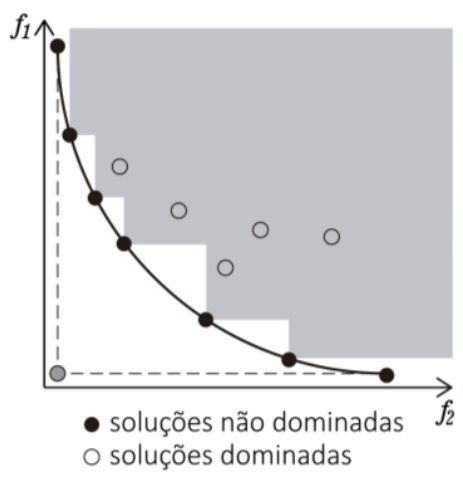

(b)

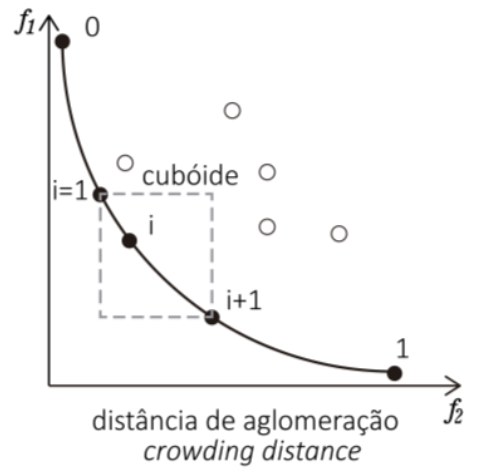

(c)

Fonte: adaptado de DEB (2001).

Neste espaço são representados pontos definidos pelos vetores objetivo, que correspondem às soluções. Dentre elas, há pontos que representam soluções dominadas e soluções não dominadas (Figura 4b), sendo essas últimas as que definem a Fronteira de Pareto. Determinada solução domina outra quando apresenta desempenho igual em todas as funções-objetivo ou superior em ao menos uma função-objetivo. Na Figura 4a é apresentada a solução que melhor contempla o objetivo 1, a que melhor contempla o objetivo 2 e o ponto ideal que corresponde à projeção do melhor resultado para ambas as funções-objetivo. Dessa forma, diante de objetivos conflitantes, geralmente a solução não é única, mas é apontado um conjunto de soluções (não dominadas) mais adequadas ao atendimento dos diferentes objetivos.

Deb et al. (2002) propuseram um algoritmo genético, o NSGA-II, com base em uma abordagem rápida de classificação por dominação, capaz de manter uma melhor disseminação de soluções e convergir para fronteira ótima de Pareto. Apresenta característica elitista, evitando a perda de melhores soluções encontradas, utilizando-as nas próximas gerações.

No NSGA-II, a população é inicializada aleatoriamente com base no intervalo e nas restrições do problema. Identificadas as frentes de dominância e as distâncias de aglomeração, os indivíduos (pais) são cruzados (ou combinados) para criar novos indivíduos (filhos). Realizada a mutação dos novos indivíduos (filhos), a nova população é ordenada conforme sua classificação de não dominação. Gerado o conjunto de soluções não dominadas, calcula-se a distância de aglomeração, e assim selecionadas as melhores soluções para compor a nova geração. $\mathrm{O}$ algoritmo evolui até que um critério estabelecido seja alcançado, geralmente o número 
máximo de gerações. A avaliação da distância de aglomeração (Figura 4c) corresponde a quantificar o espaço ao redor de uma solução "i”. Para isso, o algoritmo calcula o perímetro do cuboide formado pelas soluções vizinhas a "i" (Figura 4c) que estão localizadas na mesma frente de dominância. A solução que introduz o maior nível de diversidade corresponde àquela com maior distância de aglomeração. (DEB, 2001).

O algoritmo genético NSGA-II, segundo diversos autores (DEB et al., 2002; NASSIF et al., 2004; BROWNLEE et al., 2011; EVINS, 2013; YU et al., 2015; BRE e FACHINOTI, 2017), destaca-se pela diversidade de soluções que apresenta e pela eficiência na otimização do desempenho de edificações, em razão de sua classificação elitista que acelera a convergência de soluções. Conforme indicam Shi et al. (2016), com base em referências, os algoritmos evolutivos pertencem à categoria mais comumente usada de algoritmos de otimização, em torno de $60 \%$ dos casos analisados. Além disso, apontam que o algoritmo NSGA-II é mais adequado para resolver problemas de otimização multiobjetivo, que são comuns no projeto de arquitetura. Também Nguyen et al. (2014) indicaram algumas razões para a popularidade do uso de algoritmos genéticos em otimização multiobjetivo, entre elas a capacidade de operar com variáveis contínuas e discretas, a possibilidade de uso de computadores multiprocessadores, a robustez na manipulação e o gerenciamento de falhas.

O processo de otimização demanda configurações de alguns parâmetros relativos ao tamanho da população, número máximo de gerações e taxas de cruzamento e de mutação. Nesse sentido, Hamdy et al. (2016) avaliaram o desempenho de sete algoritmos de otimização evolutiva multiobjetivo comumente utilizados na resolução de problemas de projetos de edificações de energia quase zero (nZEB), de baixo consumo energético. Foram investigados os efeitos relacionados com o tamanho da população e do número de gerações. Seguiu-se prioritariamente as recomendações de Chen et al. (2015) e Mauro et al. (2015), assumindo tamanhos populacionais de duas a quatro vezes maiores que o número de variáveis para problemas de pequena escala. Esses autores verificaram estabilização do processo de otimização entre 1.400 e 1.800 avaliações. Essa faixa de valores foi assim recomendada pelos autores para se estabelecer um valor mínimo necessário à otimização multiobjetivo para fins de redução do consumo de energia nas edificações.

\section{Integração das ferramentas de otimização aos programas de simulação termoenergética}

Segundo Shi et al. (2016), entre 116 referências consultadas o programa EnergyPlus é o software de simulação energética mais utilizado. Com relação às ferramentas de otimização, estas foram objeto de análise por Attia et al. (2013), Nguyen et al. (2014) e Tian et al. (2015).

Segundo Attia et al. (2013) especialistas consultados recomendam o emprego das ferramentas GenOpt, MATLAB, BeOpt e modeFRONTIER. Enquanto Tian et al. (2015) indica a não familiaridade dos arquitetos para com essas ferramentas devido a sua interface. Dessa forma, aponta como mais apropriadas para otimizar o desempenho térmico do edifício as ferramentas ARCH, MOBO, jEPlus+EA e MultiOpt, além de outras como o Módulo de Otimização do DesignBuilder, BeOpt e Opt E-Plus. Nguyen et al. (2014) relacionaram 18 ferramentas de otimização, sendo 9 com código aberto. Dentre elas, a ferramenta jEPlus+EA se destaca por possibilitar otimização multiobjetivo, realização de simulações em paralelo, estudos paramétricos, uso de algoritmos múltiplos e acoplamento com o EnergyPlus.

O jEPlus foi originalmente introduzido em 2009 como uma ferramenta paramétrica destinada ao uso no programa EnergyPlus (ZHANG, 2009). Fornece uma interface que permite que parâmetros possam ser criados ou editados, realiza a gestão de simulações simultâneas e o recolhimento dos resultados. Ao menos três estudos de autores brasileiros adotaram o programa em simulações paramétricas. Melo et al. (2015) o adotaram para um grande número de simulações, assim como Triana (2016) e Versage (2016). A partir de 2017 o jEPlus dispõe do algoritmo NSGA-II, que possibilita uma otimização multiobjetivo em conjunto com parametrização, e análise de sensibilidade, versão jEPlus+EA. As simulações podem ser executadas localmente ou on-line por meio de um computador remoto (ZHANG, 2017).

Em estudos de otimização do desempenho energético do edifício, também têm sido muito utilizados os roteiros (scripts) de automatização de tarefas em linguagem de programação. O Python, por exemplo, é uma linguagem de programação dinâmica, criada por Guido van Rossum no início dos anos 90. Apresenta código aberto, claro e curto, de rápido aprendizado e que permite um programador testar com facilidade novos recursos. É principalmente utilizada para processamento de textos e dados científicos, e por essa razão integra-se com facilidade ao programa EnergyPlus. 


\section{Iniciativas no Brasil da aplicação de otimização multiobjetivo em eficiência energética}

No Brasil, os estudos relacionados com a otimização multiobjetivo em edificações e com o uso de algoritmos genéticos são muito recentes. Martins (2014) utilizou a otimização multiobjetivo com o algoritmo genético (NSGA-II) acoplado a um algoritmo simplificado de radiosidade. O intuito foi a maximização do potencial de produção de energia nas superfícies de cobertura das edificações e a minimização dos ganhos solares nas fachadas. A pesquisa utilizou os programas Citysim e o modeFRONTIER, e objetivou contribuir para estudos urbanos de concepção e requalificação.

Santana (2016) tratou da otimização multiobjetivo da geometria de edificações residenciais energeticamente eficientes por meio de algoritmos genéticos, com o uso dos programas de modelagem Rhino+Grasshopper e o software EnergyPlus associado à ferramenta Archsim.

Fonseca et al. (2017) utilizaram esses mesmos programas para analisar a relação do desempenho térmico de uma edificação unifamiliar com seus custos de construção. Barros e Carlo (2017) apresentaram uma modelagem generativa integrada à eficiência energética para edificações institucionais. Lopes et al. (2017) realizaram otimização multiobjetivo do desempenho térmico de edifício comercial com a utilização do EnergyPlus acoplado ao programa MATLAB. Como critérios para otimização foram estabelecidos a demanda anual de energia elétrica e o total de horas de desconforto pelo calor.

Dalbem (2018) realizou uma otimização multiobjetivo com o EnergyPlus associado a um algoritmo evolutivo híbrido, com base nos algoritmos CMA-ES (Covariance Matrix Adaptation Evolution Strategy) e HDE (Hybrid Differential Evolution). O estudo destinou-se à minimização do consumo de aquecimento e da incidência de sobreaquecimento em uma edificação unifamiliar de interesse social com a adoção do procedimento Passivhaus.

Zemero et al. (2019) aplicaram um método de otimização baseado em simulação com o algoritmo PAES (Pareto Archived Evolutionary Strategies) objetivando o menor consumo de energia ao menor custo construtivo. Buscou-se a alteração da morfologia e elementos construtivos de uma edificação. As soluções ótimas alcançaram 50\% de economia de energia com um retorno de investimento inferior a três anos.

\section{Método}

Este artigo corresponde à etapa de um estudo maior focado na obtenção de edificações mais eficientes energeticamente para a Região Sul do Brasil com a adoção de estratégias que possam ser adotadas prioritariamente na fase de projeto. Este estudo reflete uma aproximação dos autores com os processos de otimização por meio de programas computacionais e códigos de programação. O método é apresentado inicialmente com a caracterização do modelo construtivo e arquivo climático adotados no experimento. Na sequência são apresentadas as etapas constituintes do processo de otimização, e as técnicas computacionais utilizadas.

\section{Caracterização do modelo construtivo}

O estudo foi aplicado a uma edificação, considerada como um modelo hipotético e simplificado de única zona térmica, com área de $12 \mathrm{~m}^{2}$ e dimensões de $3 \mathrm{~m}$ de largura, $4 \mathrm{~m}$ de profundidade e $3 \mathrm{~m}$ de altura. A face frontal apresenta uma janela centrada e anteparos horizontais e verticais para fins de sombreamento, conforme indicado na Figura 5.

\section{Figura 5 - Modelo hipotético simplificado}

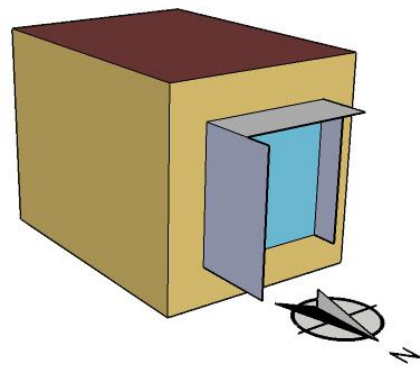

Nota: a direção indicada é meramente ilustrativa. 
O presente estudo cria um espaço de busca pela melhor solução com a alteração de importantes variáveis da construção relativos à orientação solar, propriedades dos materiais opacos da envoltória (parede e cobertura), percentual de área de janela e proteção solar.

A escolha das variáveis baseia-se no estudo de Silva e Ghisi (2013), que analisaram os parâmetros construtivos que mais influenciam nos graus-hora de resfriamento, no consumo relativo com aquecimento e com refrigeração para um modelo habitacional na cidade de Florianópolis, SC, localizada na Região Sul do Brasil. Para o consumo relativo com refrigeração, verificaram a importância da absortância solar e a emissividade da cobertura, o contato do piso com o solo e o sombreamento das aberturas. Para o consumo com aquecimento, verificaram a influência dos valores da emissividade e absortância da cobertura, da transmitância das paredes internas e externas, da capacidade térmica das paredes externas e o contato do piso com o solo. As aberturas foram consideradas sombreadas por persianas.

A Tabela 1 apresenta as sete variáveis consideradas para este trabalho, na qual são especificados os limites e a quantidade de níveis. Adotou-se para o sombreamento das aberturas proteções solares (brises) horizontais e verticais.

A Tabela 2 apresenta os níveis adotados de variação. Para orientação solar foram adotados 8 níveis iniciando em $0^{\circ}$ (correspondente ao norte) e variação em $45^{\circ}$. Para transmitância térmica da parede foram adotados 5 níveis correspondentes à espessura do isolamento térmico em lã de rocha $(25 \mathrm{~mm}, 50 \mathrm{~mm}, 75 \mathrm{~mm}, 100 \mathrm{~mm})$ aplicado externamente em parede convencional de alvenaria (tijolo de 6 furos e acabamento em reboco). Para absortância solar da cobertura foram adotados 4 níveis, correspondentes à cor do telhado. Neste estudo, as nove variações associadas ao tamanho da janela são indicadas em percentuais em relação à área de parede. Relativo às proteções solares, a projeção horizontal corresponde a um percentual em relação à largura da janela e as projeções verticais correspondem a um percentual da altura da janela. Essas relações percentuais adotadas foram estabelecidas para facilitar o processo automatizado da entrada de dados permitidos pelo software. Para cada uma das proteções solares foram adotados 5 níveis.

A Tabela 3 apresenta as propriedades térmicas dos demais materiais utilizados, que atendem aos requisitos do RTQ-R (INMETRO, 2012) para Zona Bioclimática 1 (ABNT, 2005).

Para o modelo é adotada ventilação natural, fixada em 1,5 troca de ar por hora, uma ocupação de 2 pessoas e ganhos internos de equipamentos e iluminação de $1,5 \mathrm{~W} / \mathrm{m}^{2}$ e $6 \mathrm{~W} / \mathrm{m}^{2}$, respectivamente. Os padrões de ocupação e de uso da iluminação artificial foram adotados conforme os indicados no RTQ-R.

Tabela 1 - Variáveis de construção

\begin{tabular}{c|c|c|c|c|c|c|c}
\hline & $\mathbf{1}$ & $\mathbf{2}$ & $\mathbf{3}$ & $\mathbf{4}$ & $\mathbf{5}$ & $\mathbf{6}$ & $\mathbf{7}$ \\
\cline { 2 - 8 } Variáveis & $\begin{array}{c}\text { Orientação } \\
\text { Solar } \\
\text { (ORI) }\end{array}$ & $\begin{array}{c}\text { Transmitância } \\
\text { térmica da } \\
\text { parede } \\
\text { (PAR) }\end{array}$ & $\begin{array}{c}\text { Absortância } \\
\text { solar da } \\
\text { cobertura } \\
\text { (COB) }\end{array}$ & $\begin{array}{c}\text { Percentual } \\
\text { de área de } \\
\text { janela } \\
\text { (JAN) }\end{array}$ & $\begin{array}{c}\text { Proteção } \\
\text { solar } \\
\text { horizontal } \\
\text { (PHO) }\end{array}$ & $\begin{array}{c}\text { Proteção } \\
\text { solar } \\
\text { vertical } \\
\text { esquerda } \\
\text { (PVE) }\end{array}$ & $\begin{array}{c}\text { Proteção } \\
\text { solar } \\
\text { vertical } \\
\text { direita } \\
\text { (PVD) }\end{array}$ \\
\hline Unidade & 0 & $\mathrm{~W} / \mathrm{m}^{2} \mathrm{~K}$ & - & $\%$ & $\%$ & $\%$ & $\%$ \\
\hline $\begin{array}{c}\text { Limite } \\
\text { Inferior }\end{array}$ & 0 & 0,38 & 0,3 & 10 & 20 & 20 & 20 \\
\hline $\begin{array}{c}\text { Limite } \\
\text { Superior }\end{array}$ & 315 & 2,38 & 0,9 & 90 & 100 & 100 & 100 \\
\hline $\begin{array}{c}\text { Qtd. de } \\
\text { Níveis }\end{array}$ & 8 & 5 & 4 & 9 & 5 & 5 & 5 \\
\hline
\end{tabular}

Tabela 2 - Níveis de variação

\begin{tabular}{l|l|l}
\hline & \multicolumn{1}{|c|}{ Variáveis } & \multicolumn{1}{c}{ Níveis } \\
\hline 1 & Orientação solar (Azimute) $\left[{ }^{\circ}\right]$ & $0 ; 45 ; 90 ; 135 ; 180 ; 225 ; 270 ; 315$ \\
2 & Transmitância térmica da parede $\left[\mathrm{W} / \mathrm{m}^{2} \mathrm{~K}\right]$ & 0,$38 ; 0,48 ; 0,65 ; 1,02 ; 2,38$ \\
3 & Absortância solar da cobertura [] & 0,$3 ; 0,5 ; 0,7 ; 0,9$ \\
4 & Percentual de área de janela $[\%]$ & $10 ; 20 ; 30 ; 40 ; 50 ; 60 ; 70 ; 80 ; 90$ \\
5 & Proteção solar horizontal $[\%]$ & $20 ; 40 ; 60 ; 80 ; 100$ \\
6 & Proteção solar vertical esquerda $[\%]$ & $20 ; 40 ; 60 ; 80 ; 100$ \\
7 & Proteção solar vertical direita [\%] & $20 ; 40 ; 60 ; 80 ; 100$ \\
\hline
\end{tabular}

516 Linczuk, V. C. C.; Bastos, L. E. G. 
Tabela 3 - Propriedades térmicas dos materiais

\begin{tabular}{|c|c|c|}
\hline & Transmitância térmica $\left[\mathrm{W} / \mathrm{m}^{2} \mathrm{~K}\right]$ & Absortância solar \\
\hline $\begin{array}{l}\text { Parede } \\
\text { (tijolo } 6 \text { furos }+ \text { reboco }+ \\
\text { isolamento) }\end{array}$ & Variável & 0,5 \\
\hline $\begin{array}{l}\text { Piso } \\
\text { (laje em concreto + contrapiso) }\end{array}$ & 4,04 & 0,5 \\
\hline $\begin{array}{l}\text { Cobertura } \\
\text { (manta térmica }+ \text { telha cerâmica) }\end{array}$ & 2,30 & Variável \\
\hline & Transmitância térmica $\left[\mathrm{W} / \mathrm{m}^{2} \mathrm{~K}\right]$ & SHGC \\
\hline Vidro comum $3 \mathrm{~mm}$ & 5,894 & 0,861 \\
\hline
\end{tabular}

\section{Caracterização do clima de Curitiba, PR}

A simulação ocorre para um ano inteiro (8.760 horas) com base no arquivo climático INMET 838420 da cidade de Curitiba, PR, ano de referência 2001-2010 (LABEEE, 2018).

A cidade de Curitiba, PR, de clima temperado, localizada na Região Sul do Brasil, é representativa da Zona Bioclimática 1, compreendendo as áreas mais frias do país, em geral localidades de maior altitude. Apresenta em torno de $20 \%$ das horas do ano em conforto e $70 \%$ em desconforto por frio (GOULART et al., 1998). No inverno há ocorrência de geadas e registros de temperaturas mínimas próximas de $0{ }^{\circ} \mathrm{C}$. Apresenta temperatura média anual em torno de $17{ }^{\circ} \mathrm{C}$, umidade relativa média anual de $78.7 \%$ e $1.575 \mathrm{~mm}$ de precipitação total anual. A Tabela 4 apresenta os dados climáticos de Curitiba, PR, e a Figura 6 a relação entre os registros de temperatura mensal (médias, mínimas e máximas) e a faixa de conforto para $80 \%$ de aceitabilidade, conforme ASHRAE 55 (2017).

\section{Processo de otimização}

O processo consiste em três etapas gerais: pré-processamento, otimização e pós-processamento (NGUYEN et al., 2014). A primeira etapa contempla a formulação do problema com a definição das equações para as funções-objetivo e, eventualmente, as restrições que conduzem ao processo de otimização. Considerou-se como objetivo 1 a minimização do indicador graus-hora para aquecimento $(\mathrm{GHa})$, com base na temperatura de $18{ }^{\circ} \mathrm{C}$, e como objetivo 2 a minimização do indicador graus-hora para resfriamento (GHr) da edificação, com base na temperatura de $24^{\circ} \mathrm{C}$, e não foram estabelecidas restrições ao processo de otimização.

$\mathrm{O}$ indicador graus-hora refere-se ao somatório, a cada hora, da diferença da temperatura abaixo da temperatura de referência para aquecimento, e acima da temperatura de referência para resfriamento. A Equação 1 e a Equação 2 apresentam a expressão para o cálculo de graus-hora para aquecimento (GHa) e graus-hora para resfriamento $\mathrm{GHr})$, respectivamente.

$G H a=\sum_{i=1}^{8760} T b-T \quad\left(\right.$ se $\left.T<T b^{\circ} C\right)$

Eq. 1

$G H r=\sum_{i=1}^{8760} T-T b \quad\left(\right.$ se $\left.T>T b^{\circ} C\right)$

Eq. 2

Onde:

$T$ - temperatura média horária operativa $\left({ }^{\circ} \mathrm{C}\right)$; e

$\mathrm{Tb}$ - temperatura de referência (base).

A temperatura de $18{ }^{\circ} \mathrm{C}$ é adotada com base em normas internacionais e por Givoni (1992) como o limite inferior da faixa de conforto para edificações naturalmente ventiladas no Brasil. Já a temperatura de $24{ }^{\circ} \mathrm{C}$ é referência para modelagem do sistema de condicionamento de ar estabelecido no RTQ-R (INMETRO, 2012) e a sua adoção melhor expressa os resultados quando comparado com o limite superior da faixa de conforto de $29^{\circ} \mathrm{C}$.

A segunda etapa do experimento constituiu-se no processo da otimização. Durante o processo, com o auxílio de gráficos disponibilizados em tempo real pelo programa de otimização, realizou-se o monitoramento da convergência, avaliando a redução do surgimento de novas soluções de Pareto. O programa ainda permite realizar controle de interrupção do processo e a detecção de falhas ou erros de simulação por meio de registros disponibilizados. 
Tabela 4 - Dados climáticos de Curitiba, PR

\begin{tabular}{|c|c|c|c|c|c|c|c|c|c|c|c|c|c|c|}
\hline \multicolumn{4}{|l|}{ Curitiba, PR } & \multicolumn{2}{|c|}{ Latitude } & \multicolumn{2}{|c|}{-25.4} & \multicolumn{2}{|c|}{ Longitude } & \multicolumn{2}{|c|}{-49.3} & \multicolumn{2}{|c|}{ Altitude } & \multirow{2}{*}{$\begin{array}{l}924 \mathrm{~m} \\
\text { Anual }\end{array}$} \\
\hline Meses & & Jan & Fev & Mar & Abr & Mai & Jun & Jul & Ago & Set & Out & Nov & Dez & \\
\hline \multicolumn{15}{|c|}{ Temperatura } \\
\hline Média Máx & ${ }^{\circ} \mathrm{C}$ & 23.8 & 26.0 & 25.1 & 23.2 & 20.1 & 19.2 & 21.8 & 20.6 & 19.6 & 22.3 & 22.5 & 25.4 & 22.5 \\
\hline Média & ${ }^{\circ} \mathrm{C}$ & 19.6 & 20.9 & 19.9 & 17.9 & 15.0 & 14.7 & 15.4 & 15.7 & 14.6 & 17.6 & 18.0 & 19.4 & 17.4 \\
\hline Média Mín & ${ }^{\circ} \mathrm{C}$ & 16.7 & 17.2 & 16.4 & 13.7 & 10.6 & 11.2 & 10.0 & 11.8 & 10.4 & 14.3 & 15.1 & 15.0 & 13.5 \\
\hline \multicolumn{15}{|c|}{ Umidade relativa } \\
\hline Média & $\%$ & 80.8 & 77.0 & 77.3 & 80.9 & 78.2 & 83.1 & 71.1 & 77.6 & 78.3 & 82.7 & 82.0 & 76.0 & 78.7 \\
\hline \multicolumn{15}{|c|}{ Precipitação } \\
\hline Média (Total) & $\mathrm{mm}$ & 218 & 166 & 147 & 95.7 & 114 & 94.1 & 108 & 74 & 141 & 139 & 124 & 154 & 1575.8 \\
\hline
\end{tabular}

Fonte: elaborado pelos autores com base no arquivo climático INMET (LABEEE, 2018).

Figura 6 - Temperatura mensal e faixa de conforto para Curitiba, PR

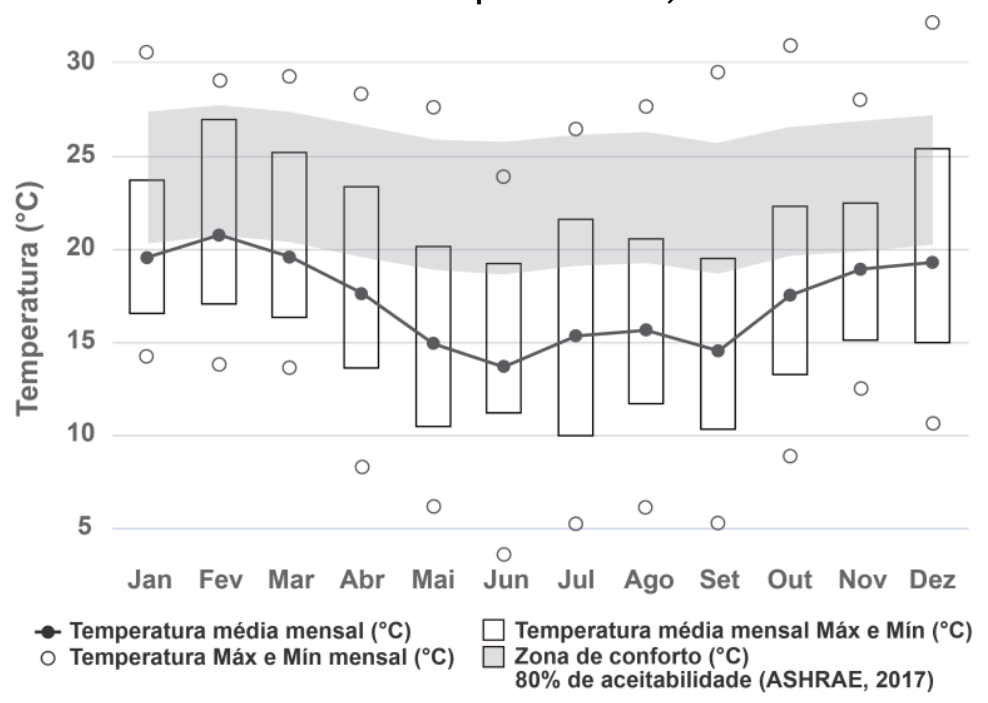

Fonte: elaborado pelos autores com base no arquivo climático INMET (LABEEE, 2018).

O algoritmo permite a obtenção de um conjunto de soluções com redução de tempo e trabalho por meio de progressivas melhorias automatizadas para assim atender aos objetivos estipulados. Os resultados são mostrados pela Fronteira de Pareto, revelando o impacto das diferentes variáveis sobre o consumo de energia do edifício.

Diante de uma grande quantidade de soluções que compõem a Fronteira de Pareto adotou-se o método de auxílio à tomada de decisão multicritério da soma ponderada Weighted Sum Model (WSM), descrito pela Equação 3 (TRIANTAPHYLLOU, 2000). Para o presente estudo atribuiu-se o mesmo peso e objetiva-se a solução $\left(S_{i}\right)$ com a menor soma ponderada.

$S_{i}^{W S M}=\min \sum_{j=1}^{n} x_{i j} w_{j}$, para $i=1,2,3, \ldots m$

Eq. 3

Onde:

$m$ - número de soluções;

$n$ - número de funções-objetivo;

$w_{j}$ - peso relativo ao indicador; e

$x_{i j}$ - valor do indicador relativo à solução analisada.

Ao final, a terceira etapa consistiu no pós-processamento, na qual foram interpretados os resultados da otimização, realizada a apresentação dos dados, e assim atendidos os objetivos inicialmente estabelecidos. 


\section{Técnicas computacionais utilizadas}

Utilizou-se o software para simulação de energia EnergyPlus (versão 8.9) associado às ferramentas de parametrização jEPlus (versão 1.7.2) e otimização jEPlus+EA (versão 1.7.7). Para realização de roteiros (scripts) em linguagem de programação e cálculo desses indicadores empregou-se um código de programação em linguagem Python (versão 3) que permitiu extrair a temperatura operativa da zona do arquivo de saída do programa de simulação EnergyPlus. O algoritmo aplicado foi o Elitist Non-Dominated Sorting Genetic Algorithm (NSGA-II), integrado ao software jEPlus+EA com as seguintes configurações: tamanho de população $=50$; taxa de cruzamento $($ crossover $)=1$; taxa de mutação $=0.2 ;$ tamanho da seleção de torneios $=2$; executadas 100 gerações.

O tamanho da população refere-se ao número de soluções a serem avaliadas em cada iteração. As configurações seguiram as recomendações de Chen et al. (2015) e Mauro et al. (2015), atendendo ao tamanho populacional de duas a quatro vezes superior ao número de variáveis. Adotou-se um tamanho de população alta, para 50 indivíduos e, ao final, foram avaliados tamanho de população para 15 e 30 indivíduos e verificados o impacto na convergência de soluções. Geralmente a escolha está relacionada ao número de núcleos de processador do computador à disposição. O número máximo de gerações refere-se ao número de iterações desejáveis. No entanto, é possível realizar a interrupção do processo antecipadamente caso as soluções encontradas sejam suficientes. Adotou-se um valor alto, de 100 gerações para se verificar com que antecipação a convergência ocorreria. Para a taxa de cruzamento, que se relaciona com a frequência que novas soluções são criadas mesclando recursos das soluções existentes, adotou-se um valor 1 , que corresponde a $100 \%$. Um valor alto é desejável para proporcionar diversidade às soluções. Para a taxa de mutação é recomendado um valor baixo para que o algoritmo não se comporte como uma tentativa e erro aleatório. Adotou-se a taxa 0,20, que corresponde a 20\%, adotado como padrão pelo software. Quanto ao tamanho da seleção de torneios, adotou-se a recomendação do software de 2 torneios. Segundo os autores quanto maior o tamanho do torneio mais difícil o algoritmo se aproxima dos objetivos desejados. Nessa configuração, a seleção de torneios escolhe duas soluções aleatoriamente da população existente e mantém a melhor com base na qualidade do ajuste dos dados (fitness), ou aptidão, com base nas funções-objetivo estipuladas. A Figura 7 apresenta o pseudocódigo do algoritmo NSGA-II.

O computador utilizado apresenta processador de 3,7 Ghz com 8 núcleos (16 threads) e 32 GB de memória RAM, o que possibilita processar tarefas simultâneas e reduzir o tempo de espera.

Figura 7 - Pseudocódigo do algoritmo NSGA-II

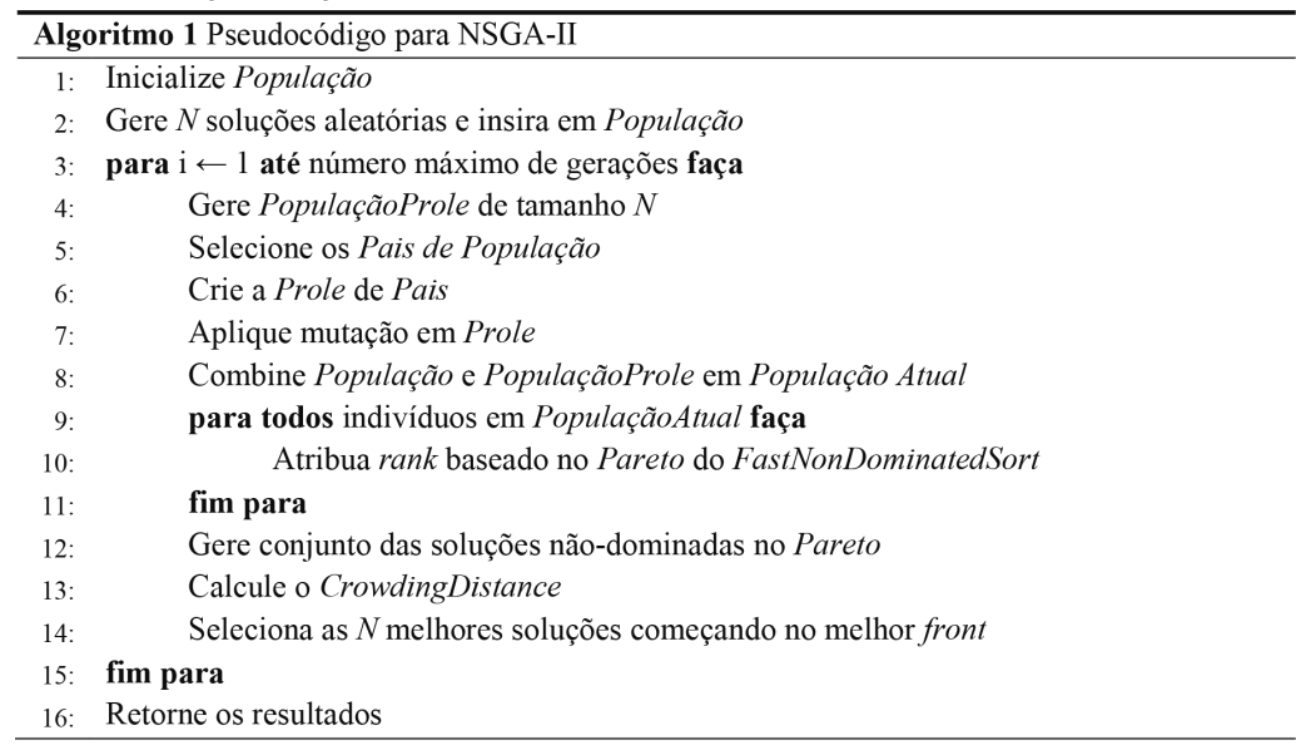

Fonte: Lacerda et al. (2016). 


\section{Configurações no software jEPlus}

A Figura 8 apresenta a interface gráfica do usuário para o software jEPlus, no qual é elaborado o projeto de parametrização. A tela inicial é dividida em um painel de controle e um painel de edição e visualização de registros de saída. No painel de controle são selecionados os arquivos de entrada complementares ao projeto:

(a) arquivo climático com extensão .EPW (Energyplus Weather Data);

(b) arquivo do modelo de construção com extensão .IDF (Input Data File); e

(c) arquivo com extensão .RVI/RVX (Report Variable Input), que define a fonte e as variáveis a serem extraídas dos arquivos de saída do software de simulação EnergyPlus. Em uma estrutura denominada "árvore de parâmetros" as variáveis são sistematizadas.

\section{Configurações no software jEPlus+EA}

A Figura 9 apresenta a interface gráfica do usuário para o software jEPlus+EA, que se constitui no motor para processo de otimização. Para iniciar o processo é necessário importar o projeto desenvolvido no software jEPlus. A tela inicial é dividida em um painel de controle, um painel de edição e um painel do modo simulação (local ou por meio de um servidor on-line remoto). No painel de controle são mostradas as variáveis, a quantidade de combinações possíveis, os objetivos e as restrições definidos no projeto de parametrização. No painel de edição são possibilitadas as configurações de escolha do algoritmo, o tamanho da população, o número de gerações, a taxa de cruzamento, a taxa de mutação e o modo de seleção.

Depois de inicializada a otimização, o software permite o acompanhamento do processo por meio de telas e gráficos que mostram a convergência, os resultados obtidos no gráfico de dispersão, o histograma das variáveis, a planilha e o relatório para detecção de falhas ou erros de simulação, conforme Figura 10.

\section{Roteiros em linguagem Python}

A Figura 11 apresenta os roteiros (scripts) em linguagem de programação Python que permitiu extrair a temperatura operativa da zona do arquivo de saída do programa de simulação EnergyPlus e realizar o cálculo de graus-hora aquecimento e graus-hora resfriamento com base nas temperaturas $18{ }^{\circ} \mathrm{C}$ e $24{ }^{\circ} \mathrm{C}$, respectivamente.

Figura 8 - Interface gráfica do software jEPlus

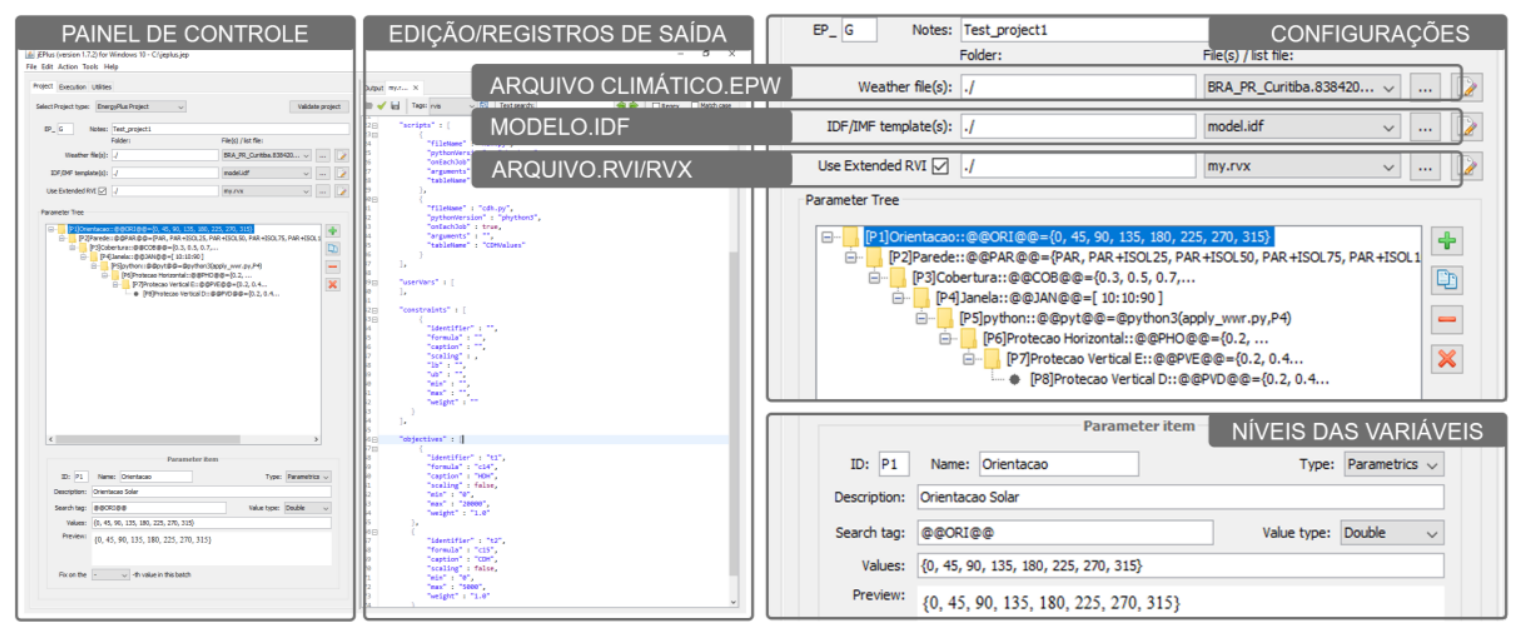

Fonte: adaptado a partir do software jEPlus. 


\section{Resultados e discussões}

Em um espaço de busca de 180.000 possibilidades, que compreende o total de combinações entre a quantidade de níveis das variáveis, foram avaliados 3.023 casos em 100 gerações, conforme estipulado o critério de interrupção do processo, por um período de 123 minutos. A Figura 12 mostra o crescimento da população ao longo das gerações e o número de soluções na Fronteira de Pareto, conjunto de soluções não dominadas que atendem aos objetivos propostos. É possível verificar que a partir de $45^{\text {a }}$ geração, avaliados aproximadamente 1.800 casos, o número de novas soluções na Fronteira de Pareto foi reduzido, denotando a estabilização do processo de otimização e concordância com a quantidade de avaliações sugeridas por Hamdy et al. (2016) como mínima necessária à otimização multiobjetivo para fins de redução do consumo de energia de edificações.

A Figura 13 apresenta a evolução dos resultados alcançados no Diagrama de Pareto desde a população inicial $(\mathrm{Ge} 0)$ até a geração 75 (Ge75). É possível identificar que embora se acentue a definição da Fronteira de Pareto, pela sua característica elitista, o algoritmo diversifica a sua procura, buscando soluções com os mais diversos níveis de variáveis. Nota-se também que dois conjuntos são evidenciados e assim se comportam refletindo os resultados obtidos nos indicadores com ou sem a presença de isolamento térmico na face externa à parede da edificação, indicando melhores resultados com a aplicação.

A Figura 14 apresenta o Diagrama de Pareto para a geração 100 (Ge100), onde estão representados graficamente:

(a) a solução de melhor resultado para minimização do GHa (S1); o melhor resultado para minimização do $\mathrm{GHr}(\mathrm{S} 2)$; e

(b) a solução que contempla a menor soma ponderada (S3).

O ponto (P1) representa o pior resultado para ambos os indicadores. A Tabela 5 apresenta os níveis adotados para cada variável dos casos identificados na Figura 14.

Figura 12 - Processo de otimização

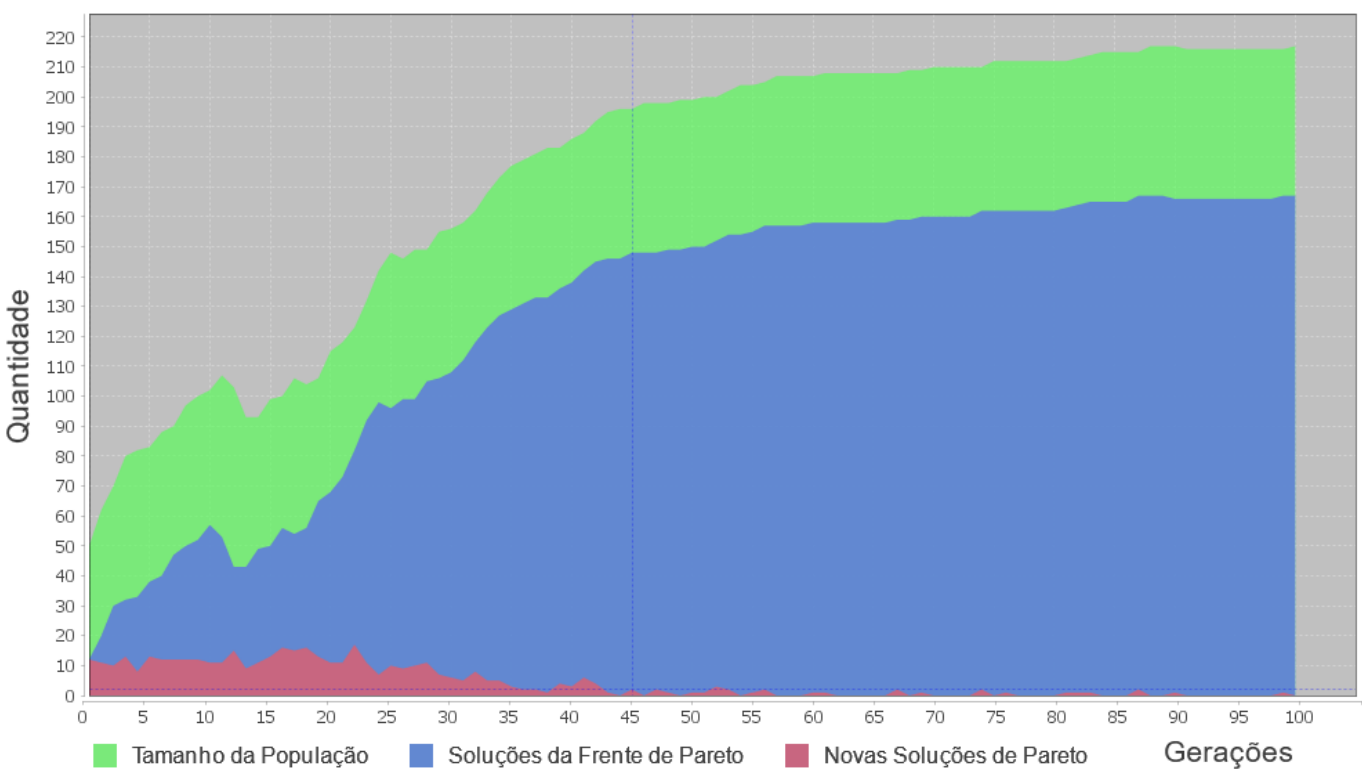

Fonte: adaptado a partir de gráfico disponibilizado pelo jEPlus+EA. 
Figura 13 - Evolução do Diagrama de Pareto
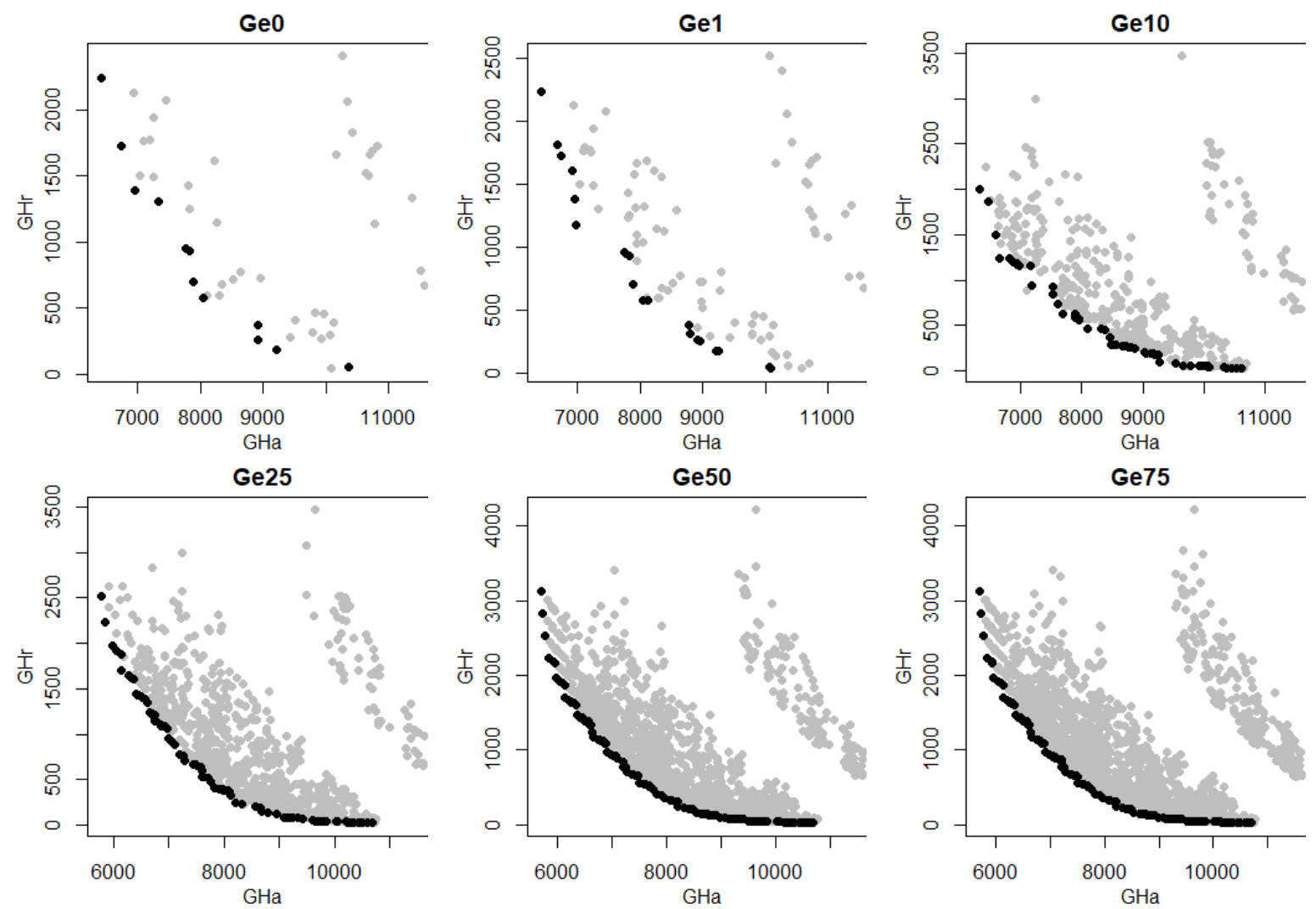

Figura 14 - Diagrama de Pareto para a Geração 100

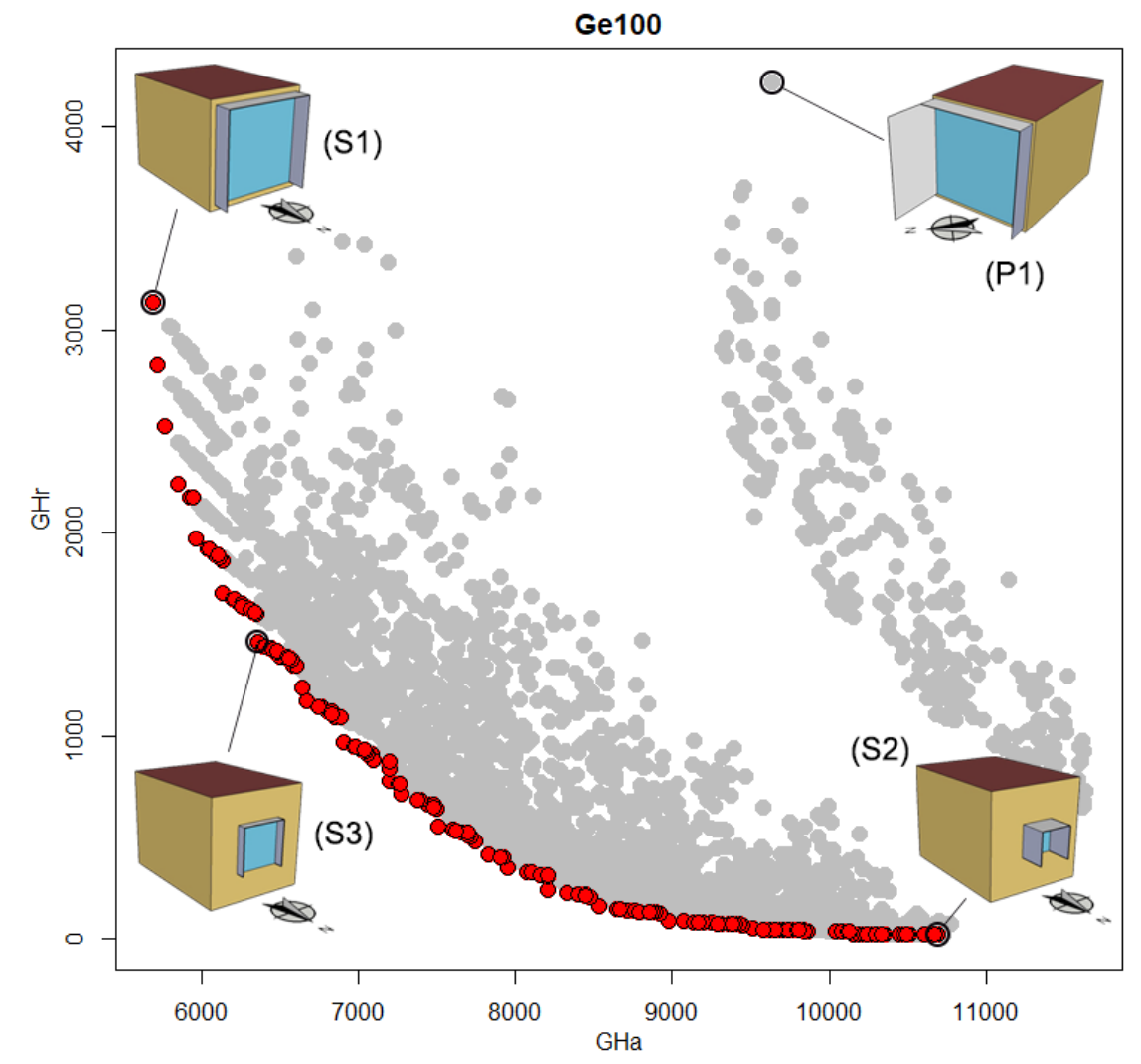


Tabela 5 - Níveis das variáveis adotados em casos identificados

\begin{tabular}{c|c|c|c|c|c|c|c}
\hline Variáveis & ORI [ ${ }^{\circ}$ ] & PAR [W/m $\mathbf{m}^{2}$ ] & COB [ ] & JAN [\%] & PHO [\%] & PVE [\%] & PVD [\%] \\
\hline S1 & 0 & 0,38 & 0,3 & 80 & 20 & 20 & 20 \\
S2 & 0 & 0,38 & 0,9 & 10 & 80 & 80 & 80 \\
S3 & 0 & 0,38 & 0,9 & 20 & 20 & 20 & 20 \\
P1 & 315 & 2,38 & 0,9 & 90 & 20 & 60 & 20 \\
\hline
\end{tabular}

Observa-se que as soluções com menor número de GHa apresentaram, por sua vez, maior número de GHr. Especialmente em regiões que apresentam estações bem marcadas de inverno e verão isso tende a ocorrer.

A Figura 15 mapeia as relações entre os diferentes níveis das variáveis que participaram do processo de combinação e que geraram diferentes resultados para os indicadores estipulados. Compõem o gráfico os 3.023 casos avaliados em todo o processo de otimização. Em destaque a solução que obteve a menor soma ponderada dos indicadores: orientação solar norte, parede em alvenaria com isolamento (lã de rocha) externo de $100 \mathrm{~mm}$, alta absortância solar da telha $(0,9)$, pequena área de janela (20\% em relação à área de parede), e brises de pequenas dimensões. Em geral a quantidade de GHa foi bem superior à de GHr, como é possível verificar no gráfico onde foram plotados as quantidade mínimas e máximas (GHa: 5.696,30 - 11630,79 ; GHr: 20,76 - 4.215,92). No gráfico de coordenadas paralelas cada barra vertical representa uma variável e em sua própria escala, incluso, em unidades diferentes. Os valores são identificados através de séries de linhas conectadas em cada eixo vertical.

A Figura 16 apresenta os parâmetros que compõem as soluções na Fronteira de Pareto da geração 100. Foram 167 soluções que em sua totalidade apresentaram orientação norte e isolamento térmico de $100 \mathrm{~mm}$, transmitância térmica de $0,38 \mathrm{~W} / \mathrm{m}^{2} \mathrm{~K}$. Verificou-se também que nenhuma das soluções adotou porcentagem de área de janela acima de $80 \%$ em relação à área de parede e um brise horizontal com dimensões acima de $80 \%$ da largura da janela. As variáveis combinadas beneficiaram alternadamente uma redução de GHa ou de $\mathrm{GHr}$.

A Figura 17 apresenta os parâmetros que compõem as 25 melhores soluções na Fronteira de Pareto da geração 100, e que obtiveram a menor soma ponderada. Observa-se que as soluções apresentaram alta absortância solar da telha, variando entre 0,7 e 0,9, área de janela inferior a $50 \%$ em relação à área de parede, brise horizontal de pequenas dimensões, porém maior variação nas dimensões para os brises verticais.

Embora o número realizado de simulações reflita apenas $1,68 \%$ das combinações possíveis, o processo de otimização por meio do algoritmo NSGA-II promoveu uma diversidade de soluções. A Figura 18 apresenta o número de casos em que os níveis de variação foram adotados no processo de otimização. Verificou-se ao menos 100 casos para cada um dos níveis. É possível identificar aqueles níveis que são mais influentes, que possibilitam melhores soluções e são mantidos nas gerações seguintes, desequilibrando a quantidade de aplicações. A adoção de orientação solar norte e isolamento térmico de $100 \mathrm{~mm}$ na face externa da parede apresentaram significativa influência para melhoria das condições ambientais internas, e por esse motivo tiveram aplicações em mais casos simulados.

Após o estudo finalizado, realizou-se um teste de convergência com a alteração do tamanho da população inicialmente estipulada para 50 indivíduos. Passou-se a contar em dois testes seguintes com 15 indivíduos e 30 indivíduos, contemplando uma proporção de 2 a 3 vezes maior que a quantidade de variáveis, mantendo as demais configurações fixas. Em 100 gerações para uma população de 15 indivíduos foram avaliados 1.157 casos e obtiveram-se 121 soluções de Pareto em um tempo de 52 minutos. Com a mesma quantidade de gerações, para uma população de 30 indivíduos foram avaliados 1.922 casos e obtiveram-se 148 soluções de Pareto em um tempo de 83 minutos. Se para 50 indivíduos a aparente convergência ocorreu na $45^{\mathrm{a}}$ geração (avaliados aproximadamente 1.800 casos), identificou-se que para 15 e 30 indivíduos ocorreram na $90^{\mathrm{a}}$ (avaliados 1.083 casos) e $60^{\mathrm{a}}$ gerações (avaliados 1.365 casos), respectivamente. Observa-se, portanto, que não apenas o número de casos avaliados é determinante para a convergência, assim como o número de iterações, ou seja, de gerações.

\section{Considerações finais}

A revisão bibliográfica realizada e o estudo aplicado permitem afirmar que a otimização com o uso de algoritmos genéticos abre caminho como um importante método para a busca de soluções para problemas multiobjetivos em que ocorrem conflitos. Esse método é especialmente pertinente para climas temperados e 
quando se pretende alcançar ótima redução do consumo de energia para condicionamento térmico da edificação.

Diante da especificidade climática da Região Sul e da necessidade de adoção de estratégias que ora beneficiam a redução do indicador graus-hora para aquecimento, ora prejudicam a redução dos indicadores graus-hora para resfriamento, e vice-versa, o método de otimização multiobjetivo por meio de algoritmos genéticos revela um conjunto de soluções não dominadas, por meio do diagrama de Pareto, que correspondem às melhores soluções.

Figura 15 - Variáveis e níveis que compõem os casos avaliados até a geração 100

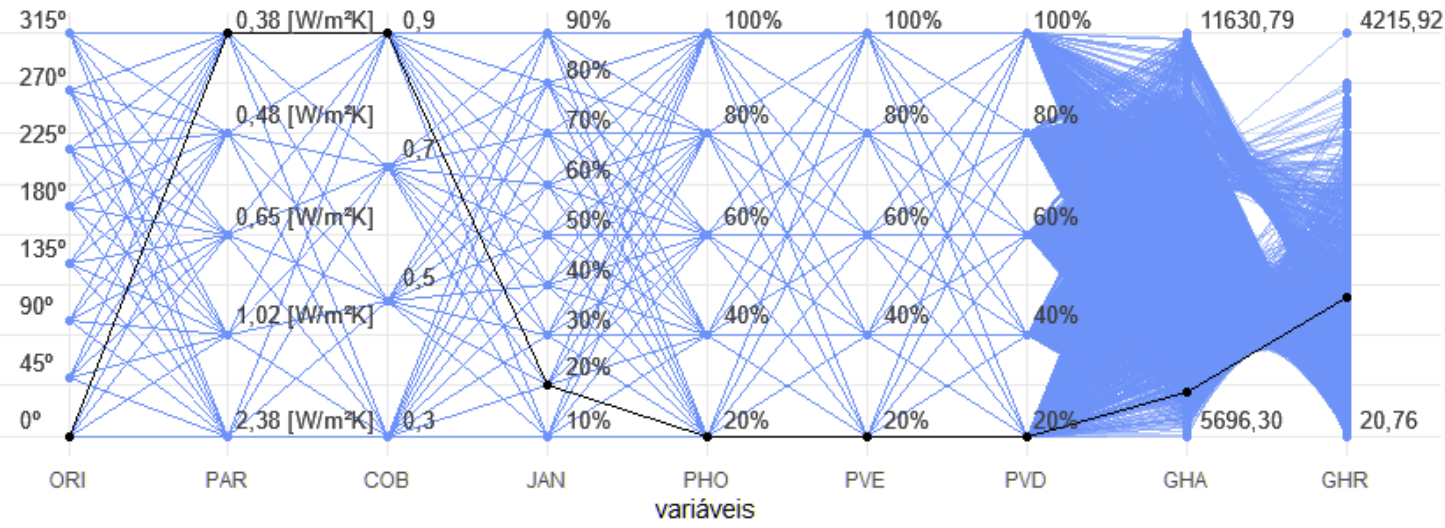

Figura 16 - Variáveis e níveis que compõem as soluções na Fronteira de Pareto

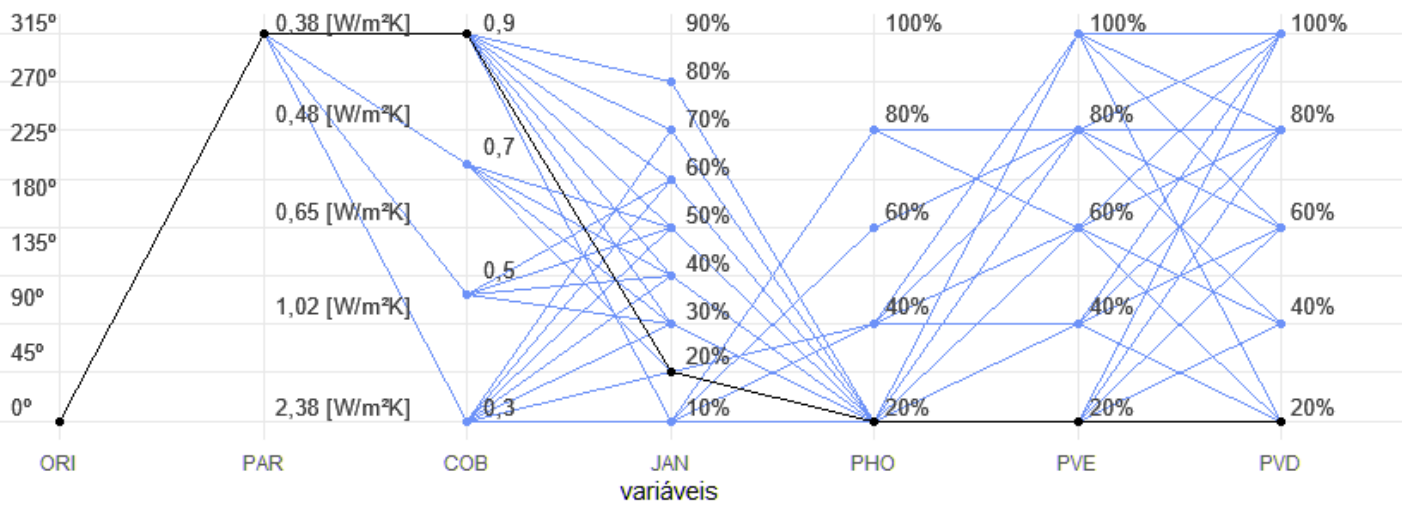

Figura 17 - Variáveis e níveis das 25 soluções na Fronteira de Pareto que obtiveram a menor soma ponderada

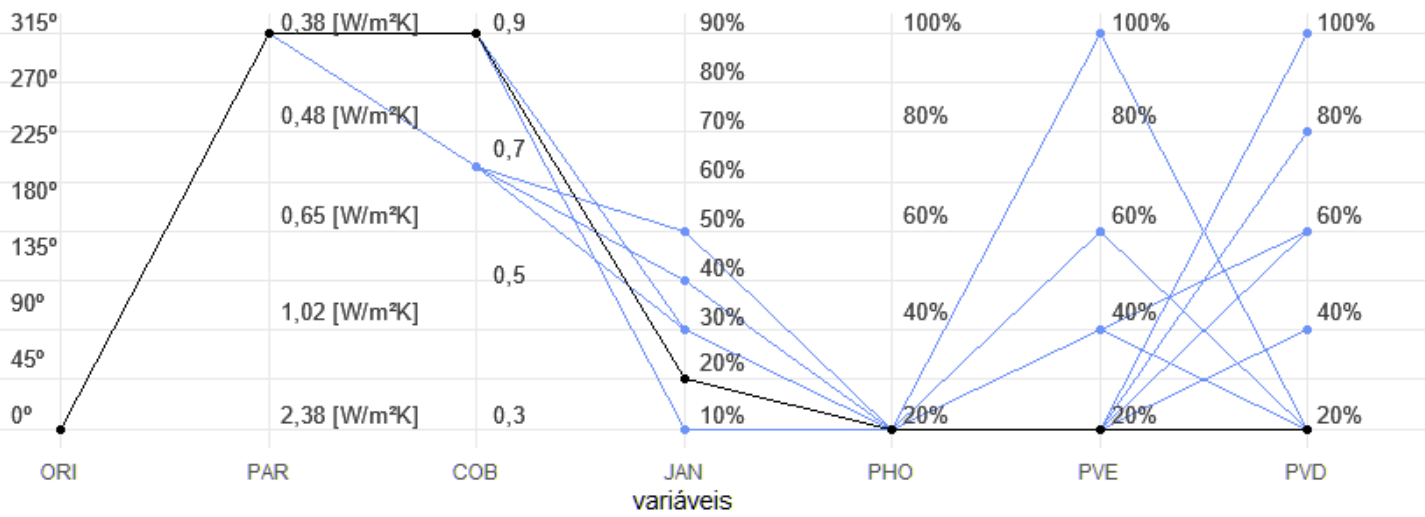


Figura 18 - Quantidade de casos em que os níveis de variação foram adotados
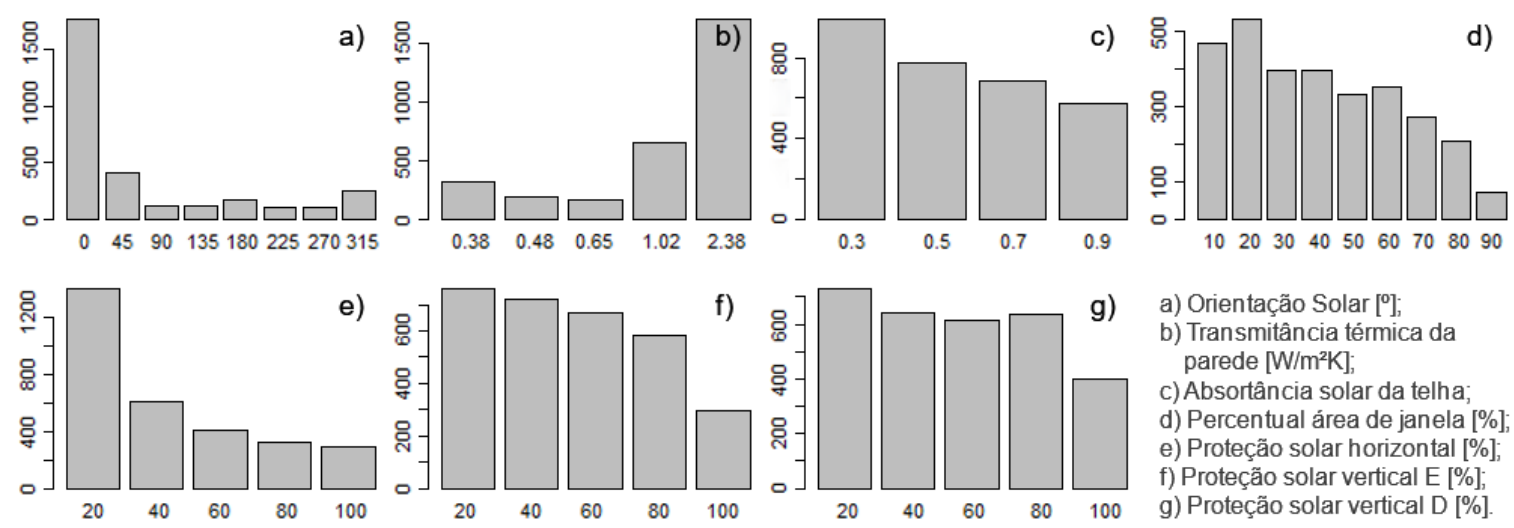
a) Orientação Solar [ [ $]$;
b) Transmitância térmica da parede $\left[\mathrm{W} / \mathrm{m}^{2} \mathrm{~K}\right]$
c) Absortância solar da telha;
d) Percentual área de janela [\%]
e) Proteção solar horizontal [\%]
f) Proteção solar vertical E [\%];
g) Proteção solar vertical D [\%].

A vantagem da utilização de um método multiobjetivo em comparação a um método mono-objetivo, especialmente quando há objetivos conflitantes, é permitir que a decisão sobre a escolha da solução possa ocorrer após o processamento, verificando não apenas a solução mais adequada, mas um conjunto de soluções. Embora posteriormente tenha-se adotado o método da soma ponderada para elencar 25 melhores soluções, como também a solução que apresentou destaque, reduzindo o problema em mono-objetivo, o processo de busca de soluções pelo método multiobjetivo possibilita maior diversidade de soluções (DEB, 2001), garantido pelo operador de seleção. Esse processo também permite identificar mais facilmente as variáveis e os respectivos níveis que melhor atendem à expectativa de minimização dos objetivos elencados.

Em razão das simulações terem sido realizadas para um modelo simplificado, de única zona térmica, o presente estudo não pretende ser conclusivo com o intuito de indicar melhores estratégias a serem adotadas para edificações na Região Sul do Brasil. Apenas demonstra o potencial das ferramentas de otimização e o impacto de diferentes variáveis sobre os indicadores de graus-hora GHa e GHr que podem refletir em maior consumo de energia para aquecimento e resfriamento da edificação. Nesse momento não se contemplou o custo das decisões que poderia influenciar em muito na tomada de decisão, assim como aspectos relativos à qualidade do ar interior e iluminação natural, que passarão a compor estudos seguintes.

O estudo realizado de otimização considerou dois objetivos: a minimização dos indicadores de graus-hora para aquecimento e de graus-hora para resfriamento. É possível, no entanto, a inserção de mais um objetivo, o que produziria um diagrama tridimensional. Para o caso com mais de três objetivos, estes poderiam ser associados em uma equação com a possibilidade de atribuição de diferentes pesos. É ainda possível atribuir inúmeras restrições ao processo, possibilitando o descarte de soluções encontradas que não atendam a uma condição específica, assemelhando-se a um objetivo a ser alcançado. Pesquisadores como Seada e Deb (2016) têm avaliado o aperfeiçoamento de algoritmos no intuito de possibilitar que mais de três objetivos possam ser considerados simultaneamente.

Outro aspecto a ser observado é que a busca pelas soluções mais adequadas aos objetivos propostos apresenta significativa redução de tempo associado ao uso de algoritmos e computadores multiprocessadores, possibilitando que mais estudos possam ser realizados, e auxilia a tomada de decisão pelo projetista na fase inicial de concepção do projeto da edificação.

\section{Referências}

AMERICAN SOCIETY OF HEATING, REFRIGERATING AND AIR-CONDITIONING ENGINEERS. Standard 55: thermal environmental conditions for human occupancy. Atlanta, 2017.

ASSOCIAÇÃO BRASILEIRA DE NORMAS TÉCNICAS. NBR 15220-3: desempenho térmico de edificações: parte 3: zoneamento bioclimático brasileiro e diretrizes construtivas para habitações unifamiliares de interesse social. Rio de Janeiro, 2005.

ATTIA, S. Computational optimization for Zero Energy Building design: interviews with 28 international experts. International Energy Agency (IEA) Task 40: Towards Net Zero Energy Buildings

Subtask B . Louvain la Neuve : Université Catholique de Louvain, 2012. 
ATTIA, S. et al. Assessing gaps and needs for integrating building performance optimization tools in net zero energy buildings design. Energy and Buildings, v. 60, p. 110-124, 2013.

BARROS, N. N.; CARLO, J. C. Modelagem generativa integrada à eficiência energética: estudo da otimização da forma de edificações institucionais. Arquitetura Revista Unisinos, v. 13, n. 2, p. 100-111, 2017.

BRANCO, R.; SANTOS, C. Eficiência energética em edificações: desenvolvimento de software para auxílio de projetos de edificações sob a ótica do conforto térmico. In: ENCONTRO NACIONAL DE

ENGENHARIA DE PRODUÇÃO, 32., Bento Gonçalves, 2012. Anais [...] Bento Gonçalves, 2012.

BRE, F.; FACHINOTTI, V. A computational multi-objective optimization method to improve energy and thermal comfort in dwellings. Energy and Buildings, v. 154, p. 283-294, 2017.

BROWNLEE, A.E.; WRIGHT, J.A.; MOURSHED, M.M. A multi-objective window optimisation problem. In: ANNUAL CONFERENCE COMPANION ON GENETIC AND EVOLUTIONARY COMPUTATION, 13,. Dublin, 2011. Proceedings [...] Dublin, 2011.

CHEN, S.; MONTGOMERY, J.; BOLUFÉ-RÖHLER, A. Measuring the curse of dimensionality and its effects on particle swarm optimization and differential evolution. Applied Intelligence, v. 42, n. 3, p. 514$526,2015$.

DALBEM, R. Desempenho de edificação residencial no Sul do Brasil sob a ótica energética e econômica: da NBR 15575 a Passive House. Pelotas, 2018. 122 f. Dissertação (Mestrado em Arquitetura e Urbanismo) - Faculdade de Arquitetura e Urbanismo, Universidade Federal de Pelotas, Pelotas, 2018.

DALBEM, R. et al. Verification of the Passive House concept to the South on Brazil climate. Journal of Civil Engineering and Architecture, v. 10, p. 937-945, 2016.

DEB, K. et al. A fast and elitist multiobjective genetic algorithm: NSGA-II. IEEE Transactions on Evolutionary Computation, v. 6, n. 2, p. 182-197, 2002.

DEB, K. Multiobjective optimization using evolutionary algorithms. Chichester: John Wiley \& Sons, 2001.

DELGARM, N.; SAJADI, B.; DELGARM, S. Multi-objective optimization of building energy performance and indoor thermal comfort: A new method using artificial bee colony (ABC). Energy and Buildings, v. 131, p. 42-53, 2016.

EMPRESA DE PESQUISA ENERGÉTICA. Anuário estatístico de energia elétrica 2018: ano base 2017. Rio de Janeiro, 2018.

ENERGY PERFORMANCE OF BUILDINGS DIRECTIVE. Diretiva 2010/31/EU do Parlamento Europeu e do Conselho de 19 de Maio de 2010 relativa ao desempenho energético dos edifícios (reformulação). Jornal Oficial da União Europeia, L 153/13, 2010.

EVINS, R. A review of computational optimization methods applied to sustainable building design.

Renewable and Sustainable Energy Reviews, v. 22, p. 230-245, 2013.

FONSECA, L. et al. Otimização multiobjetivo das dimensões dos ambientes de uma residência unifamiliar baseada em simulação energética e estrutural. Ambiente Construído, Porto Alegre, v. 17, n. 1, p. 267-288, 2017.

FOSSATI, M. et al. Building energy efficiency: an overview of the Brazilian residential labeling scheme.

Renewable and Sustainable Energy Reviews, v. 65, p. 1216-1231, 2016.

GIVONI, B. Comfort, climate analysis and building design guidelines. Energy and Building, v. 18, p. 1123, 1992.

GOULART, S.; LAMBERTS, R.; FIRMINO, S. Dados climáticos para projeto e avaliação energética de edificações para 14 cidades Brasileiras. 2. ed. Florianópolis: Núcleo de Pesquisa em Construção da UFSC, 1998.

HAMDY, M.; NGUYEN, A.; HENSEN, J.L. A performance comparison of multi-objective optimization algorithms for solving nearly-zero-energy-building design problems. Energy and Buildings, v. 121, p. 57$71,2016$.

HOLLAND, J. Adaptation in natural and artificial systems. Ann Arbor: The University of Michigan, 1975. 
INSTITUTO NACIONAL DE METROLOGIA NORMALIZAÇÃO E QUALIDADE INDUSTRIAL. Portaria no 18, de 16 de janeiro de 2012, que regulamento Técnico da Qualidade para o Nível de Eficiência Energética de Edificações Residenciais (RTQ-R), 2012.

KHEIRI, F. A review on optimization methods applied in energy-efficient building geometry and envelope design. Renewable and Sustainable Energy Reviews, v. 92, p. 897-920, 2018.

LABORATÓRIO DE EFICIÊNCIA ENERGÉTICA EM EDIFICAÇÕES. Base de dados climáticos de municípios brasileiros INMET: arquivos em formato EPW (Energyplus Weather Data) - Atualização 2018. Disponível em: http://www.labeee.ufsc.br/ downloads/arquivos-climaticos/inmet2018. Acesso em: 20 set. 2019.

LACERDA, H. et al. Redução de Energia em Casas Inteligentes utilizando uma Abordagem Multiobjetivo baseada nos Perfis de Uso de Equipamentos. In: SYMPOSIUM ON COMPUTING SYSTEMS ENGINEERING, 6., João Pessoa, 2016. Proceedings [...] João Pessoa, 2016.

LOPES, F.; CÓSTOLA, D.; LABAKI, L. Thermal-energy performance for office buildings in Brazil using multiobjective optimization. In: PASSIVE AND LOW ENERGY ARCHITECTURE, Edinburg, 2017. Proceedings [...] Edinburg, 2017.

MACHAIRAS, V.; TSANGRASSOULIS, A.; AXARLI, K. Algorithms for optimization of building design: A review. Renewable and Sustainable Energy Reviews, v. 3, p. 101-112, 2014.

MARTINS, T. A. de L. De condicionantes solares à oportunidades de desenho urbano: otimização de tipo-morfologias urbanas em contexto de clima tropical. Rio de Janeiro, 2014. 393 f. Tese (Doutorado em Arquitetura) - Faculdade de Arquitetura e Urbanismo, Universidade Federal do Rio de Janeiro, Rio de Janeiro, 2014.

MAURO, G.M. et al. A new methodology for investigating the cost-optimality of energy retrofitting a building category. Energy and Buildings, v. 107, p. 456-478, 2015.

MELO, A. P. et al. Is Thermal insulation always beneficial in hot climate? In: BUILDING SIMULATION CONFERENCE, 14., Hyderabad, 2015. Proceedings [...] Hyderabad, 2015.

NASSIF, N.; KAJL, S.; SABOURIN, R. Evolutionary algorithms for multi-objective optimization in HVAC system control strategy. In: IEEE ANNUAL MEETING OF THE NORTH AMERICAN FUZZY INFORMATION PROCESSING SOCIETY, Banff, 2004. Proceedings [...]Banff, 2004.

NGUYEN, A.T.; REITER, S.; RIGO, P. A review on simulation-based optimization methods applied to building performance analysis. Applied Energy, v. 113, p. 1043-1058, 2014.

ØSTERGÅRD, T.; JENSEN, R.L.; MAAGAARD, S.E. Building simulations supporting decision making in early design: a review. Renewable and Sustainable Energy Reviews, v. 61, p. 187-201, 2016.

PACHECO, M. T. G. Ventilação natural e climatização artificial: crítica ao modelo superisolado para residências de energia zero em Belém e Curitiba. Florianópolis, 2014. 320 f. Tese (Doutorado em Engenharia Civil) - Universidade Federal de Santa Catarina, Florianópolis, 2014.

PACHECO, M.; LAMBERTS, R. Assessment of technical and economical viability for large-scale conversion of single family residential buildings into zero energy building in Brazil: Climatic and cultural considerations. Energy Policy, v. 63, p. 716-725, 2013.

PARETO, V. Cours D'économie Politique. Lausanne: F. Rouge, 1896.

SANTANA, L. O. Otimização multiobjetivo da geometria de edificações residenciais energeticamente eficientes por meio de algoritmos genéticos. Viçosa, 2016. $81 \mathrm{f}$. Dissertação (Mestrado em Arquitetura e Urbanismo) - Universidade Federal de Viçosa, Viçosa, 2016.

SCHNIEDERS, J. et al. Passive house for different climate zones. Darmstadt: Wolfgand Feist, Passivhaus Institut and University of Innsbruck, 2012.

SEADA, H.; DEB, K. A unified evolutionary optimization procedure for single, multiple, and many objectives. IEEE Transactions on Evolutionary Computation, v. 20, n. 3, p. 358-369, 2016.

SHI, X. et al. A review on building energy efficient design optimization from the perspective of architects. Renewable and Sustainable Energy Reviews, v. 65, p. 872-884, 2016. 
SILVA, A. S.; GHISI, E. Análise de sensibilidade global dos parâmetros termofísicos de uma edificação residencial de acordo com o método de simulação do RTQ-R. Ambiente Construído, Porto Alegre, v. 13, n. 4, p. 135-148, out./dez. 2013.

TIAN, Z. et al. Building energy optimization tools and their applicability in architectural conceptual design stage. In: INTERNATIONAL BUILDING PHYSICS CONFERENCE, 6., Torino, 2015. Proceedings [...] Torino, 2015.

TRIANA MONTES, M. A. Abordagem integrada no ciclo de vida de habitação de interesse social considerando mudanças climática. Florianópolis, 2016. 473 f. Tese (Doutorado em Engenharia Civil) Universidade Federal de Santa Catarina, Florianópolis, 2016.

TRIANTAPHYLLOU, E. Multi-criteria decision making methods: a comparative study. Dordrecht: Kluwer Academic Publishers, 2000.

TUBELO, R. et al. Cost-effective envelope optimisation for social housing in Brazil's moderate climates zones. Building and Environment, v. 133, p. 213-227, 2018.

TUBELO, R.; RODRIGUES, L.; GILLOT, M. A comparative study of the brazilian energy labelling system and the passivhaus standard for housing. Buildings, v. 4, n. 2, p. 207-221, 2014.

TUHUS-DUBROW, D.; KRARTI, M. Genetic-algorithm based approach to optimize building envelope design for residential buildings. Building and Environment, v. 45, p. 1574-1581, 2010.

VERSAGE, R. de S. Metamodelo para estimar a carga térmica de edificações condicionadas artificialmente. Florianópolis, 2016. 191 f. Tese (Doutorado em Engernharia Civil) - Universidade Federal de Santa Catarina, Florianópolis, 2016.

WASSOUF, M. De la casa pasiva al estándar Passivhaus: la arquitectura pasiva en climas cálidos. Barcelona: Gustavo Gili, 2014.

YU, W. et al. Application of multi-objective genetic algorithm to optimize energy efficiency and thermal comfort in building design. Energy and Buildings, v. 88, p. 135-143, 2015.

ZEMERO, B. R. et al. Methodology for preliminary design of buildings using multi-objective optimization based on performance simulation. Journal of Solar Energy Engineering, v. 141, n. 4, p. 1-12, 2019.

ZHANG, Y. 'Parallel' EnergyPlus and the development of a parametric analysis tool. In: CONFERENCE OF THE INTERNATIONAL BUILDING PERFORMANCE SIMULATION ASSOCIATION, 11., Glasgow, 2009. Proceedings [...] Glasgow, 2009.

ZHANG, Y.; JANKOVIC, L. JEA, an interactive optimization engine for building energy performance simulation. In: CONFERENCE OF THE INTERNATIONAL BUILDING PERFORMANCE SIMUlation ASSOCIATION, 15., San Francisco, 2017. Proceedings [...] San Francisco, 2017.

Vinícius Cesar Cadena Linczuk

Curso de Arquitetura e Urbanismo | Universidade Federal da Fronteira Sul | ERS-135, Km 72, 200 | Caixa Postal 764 | Erechim - RS - Brasil | CEP 99700-970 | Tel.: (54) 3321-7352 | E-mail: vinicius.linczuk@uffs.edu.br

\title{
Leopoldo Eurico Gonçalves Bastos
}

Programa de Pós-graduação em Arquitetura, Faculdade de Arquitetura e Urbanismo | Universidade Federal do Rio de Janeiro | Av. Pedro Calmon, 550, Cidade Universitária | CEP 21941-485 | Rio de Janeiro - RJ - Brasil | Tel.: (21) 3938-1661 | Programa de Pós Graduação Arquitetura e Cidade | Universidade Vila Velha | Av. Comissário José Dantas, 21 | Vila Velha - ES - Brasil | CEP 29102-920 | Tel.: (27) 3421-2001 | E-mail: leopoldobastos@gmail.com

\author{
Ambiente Construído \\ Revista da Associação Nacional de Tecnologia do Ambiente Construído \\ Av. Osvaldo Aranha, $99-3^{\circ}$ andar, Centro \\ Porto Alegre - RS - Brasil \\ CEP 90035-190 \\ Telefone: +55 (51) 3308-4084 \\ Fax: +55 (51) 3308-4054 \\ www.seer.ufrgs.br/ambienteconstruido \\ E-mail: ambienteconstruido@ufrgs.br
}

